\title{
Computational Comparison of Different Reagent lons in the Chemical Ionization of Oxidized Multifunctional Compounds
}

Noora Hyttinen, Rasmus V. Otkjær, Siddharth lyer, Henrik Grum

Kjaergaard, Matti P. Rissanen, Paul O. Wennberg, and Theo Kurtén

J. Phys. Chem. A, Just Accepted Manuscript • DOI: 10.1021/acs.jpca.7b10015 • Publication Date (Web): 04 Dec 2017

Downloaded from http://pubs.acs.org on December 4, 2017

\section{Just Accepted}

"Just Accepted" manuscripts have been peer-reviewed and accepted for publication. They are posted online prior to technical editing, formatting for publication and author proofing. The American Chemical Society provides "Just Accepted" as a free service to the research community to expedite the dissemination of scientific material as soon as possible after acceptance. "Just Accepted" manuscripts appear in full in PDF format accompanied by an HTML abstract. "Just Accepted" manuscripts have been fully peer reviewed, but should not be considered the official version of record. They are accessible to all readers and citable by the Digital Object Identifier (DOI®). "Just Accepted" is an optional service offered to authors. Therefore, the "Just Accepted" Web site may not include all articles that will be published in the journal. After a manuscript is technically edited and formatted, it will be removed from the "Just Accepted" Web site and published as an ASAP article. Note that technical editing may introduce minor changes to the manuscript text and/or graphics which could affect content, and all legal disclaimers and ethical guidelines that apply to the journal pertain. ACS cannot be held responsible for errors or consequences arising from the use of information contained in these "Just Accepted" manuscripts. 


\title{
Computational Comparison of Different Reagent
}

\section{Ions in the Chemical Ionization of Oxidized}

\section{Multifunctional Compounds}

\author{
Noora Hyttinen, ${ }^{a}$ Rasmus V. Otkjoer, ${ }^{b}$ Siddharth Iyer, ${ }^{a}$ Henrik G. Kjaergaard, ${ }^{b}$ Matti P. \\ Rissanen, ${ }^{c}$ Paul O. Wennberg, ${ }^{d}$ Theo Kurtén ${ }^{* a}$ \\ ${ }^{a}$ Department of Chemistry, University of Helsinki, P.O. Box 55, FI-00014, Helsinki, Finland \\ ${ }^{\mathrm{b}}$ Department of Chemistry, DK-2100 Copenhagen $\varnothing$, University of Copenhagen, Copenhagen, \\ Denmark \\ ${ }^{\mathrm{c}}$ Department of Physics, University of Helsinki, P.O. Box 64, FI-00014, Helsinki, Finland \\ ${ }^{\mathrm{d}}$ Division of Engineering and Applied Science and Division of Geological and Planetary \\ Sciences, California Institute of Technology, 1200 East California Boulevard, Pasadena, \\ California 91125, United States
}

\begin{abstract}
High pressure anion chemical ionization is commonly used for the detection of neutral molecules in the gas phase. The detection efficiency in these measurements depends on how strongly the reagent ion binds to the neutral target molecule. We have calculated the binding strength of
\end{abstract}


nitrate $\left(\mathrm{NO}_{3}^{-}\right)$, acetate $\left(\mathrm{CH}_{3} \mathrm{C}(\mathrm{O}) \mathrm{O}^{-}\right)$, lactate $\left(\mathrm{CH}_{3} \mathrm{CH}(\mathrm{OH}) \mathrm{C}(\mathrm{O}) \mathrm{O}^{-}\right)$, trifluoroacetate $\left(\mathrm{CF}_{3} \mathrm{C}(\mathrm{O}) \mathrm{O}^{-}\right.$ ), trifluoromethanolate $\left(\mathrm{CF}_{3} \mathrm{O}^{-}\right)$, bromide $\left(\mathrm{Br}^{-}\right)$and iodide $\left(\mathrm{I}^{-}\right)$reagent ions to ten different products derived from the $\mathrm{OH}$ radical initiated oxidation of butadiene. We found that the binding of these oxidation products to the reagent ions depends almost linearly on the number of oxygen atoms in the target molecule, with the precise chemical identity of the compound (e.g. the number and relative position of hydroxyl or hydroperoxy groups) playing a more minor role. For acetate, the formation free energy decreases on average by around $4 \mathrm{kcal} / \mathrm{mol}$ when the number of oxygen atoms in the sample molecule increases by one. For the other reagent ions the corresponding decrease is around $3 \mathrm{kcal} / \mathrm{mol}$. For all of the molecules studied, acetate forms the most stable clusters and $\mathrm{I}^{-}$the least stable. We also investigated the effect of humidity on the chemical ionization by calculating how strongly water molecules bind to both the reagent ions and the ion-molecule clusters. Water binds much more strongly to the reagent ion monomers compared to the reagent ion "dimers" (defined here as a cluster of the reagent anion with the corresponding neutral conjugate acid, e.g. $\left.\mathrm{HNO}_{3}\left(\mathrm{NO}_{3}{ }^{-}\right)\right)$or the ion-molecule clusters. This likely leads to a stronger humidity dependence when using reagent ions that are not able to form reagent ion dimers (such as $\mathrm{CF}_{3} \mathrm{C}(\mathrm{O}) \mathrm{O}^{-}, \mathrm{CF}_{3} \mathrm{O}^{-}, \mathrm{Br}^{-}$and $\mathrm{I}^{-}$).

\section{INTRODUCTION}

Chemical ionization combined with various types of mass spectrometers (CIMS) is a versatile tool for investigating atmospheric gas-phase reaction mechanisms and trace gas concentrations. The main limitation of the CIMS technique is that neutral gas-phase molecules can only be detected if they are ionized by the reagent ion. A large uncertainty in interpreting the quantitative results of chemical ionization measurements arises from the limited understanding of the chemical ionization process. Using the same instrument with different reagent ions for the 
chemical ionization has shown that the detection efficiency depends on both the reagent ion and the measured sample molecule. ${ }^{1,2,3}$

Figure 1 shows a schematic of the different processes in chemical ionization. The reagent ions $\left(\mathrm{Q}^{-}\right)$can ionize the sample molecules $(\mathrm{RH})$ by forming ion-molecule clusters $\left(\mathrm{RH}\left(\mathrm{Q}^{-}\right)\right)$:

$$
R H+Q^{-} \rightarrow R H\left(Q^{-}\right)
$$

In experimental conditions, some reagent ions are able to form stable reagent ion dimers $\left(\mathrm{QH}_{(\mathrm{Q}}\right.$ ) ) or hydrates $\left(\left(\mathrm{H}_{2} \mathrm{O}\right)_{n}\left(\mathrm{Q}^{-}\right)\right)$, shown in green in Figure 1. Then the chemical ionization happens through a ligand exchange reaction:

$$
\begin{aligned}
& R H+Q H\left(Q^{-}\right) \rightarrow Q H+R H\left(Q^{-}\right) \\
& R H+\left(H_{2} O\right)_{n}\left(Q^{-}\right) \rightarrow n H_{2} O+R H\left(Q^{-}\right)
\end{aligned}
$$

For instance using nitrate $\left(\mathrm{NO}_{3}{ }^{-}\right)$and acetate $\left(\mathrm{CH}_{3} \mathrm{C}(\mathrm{O}) \mathrm{O}^{-}\right)$, the reagent ion dimer plays a significant role in the chemical ionization of the sample molecules, ${ }^{1,3,4}$ while using trifluoromethanolate $\left(\mathrm{CF}_{3} \mathrm{O}^{-}\right)$and iodide $\left(\mathrm{I}^{-}\right)$, reagent ion hydrates with up to four water molecules are usually detected. ${ }^{5,6}$ The $\mathrm{H}_{2} \mathrm{O}\left(\mathrm{CF}_{3} \mathrm{O}^{-}\right)$monohydrate is detected even at low relative humidities, affecting the detection efficiencies. ${ }^{7}$ Acetate can be produced from either acetic anhydride ${ }^{8,9}$ or acetic acid, ${ }^{1}$ and acetic acid-acetate dimers $\left(\mathrm{CH}_{3} \mathrm{C}(\mathrm{O}) \mathrm{OH}\left(\mathrm{CH}_{3} \mathrm{C}(\mathrm{O}) \mathrm{O}^{-}\right)\right)$can be detected in both types of measurements.

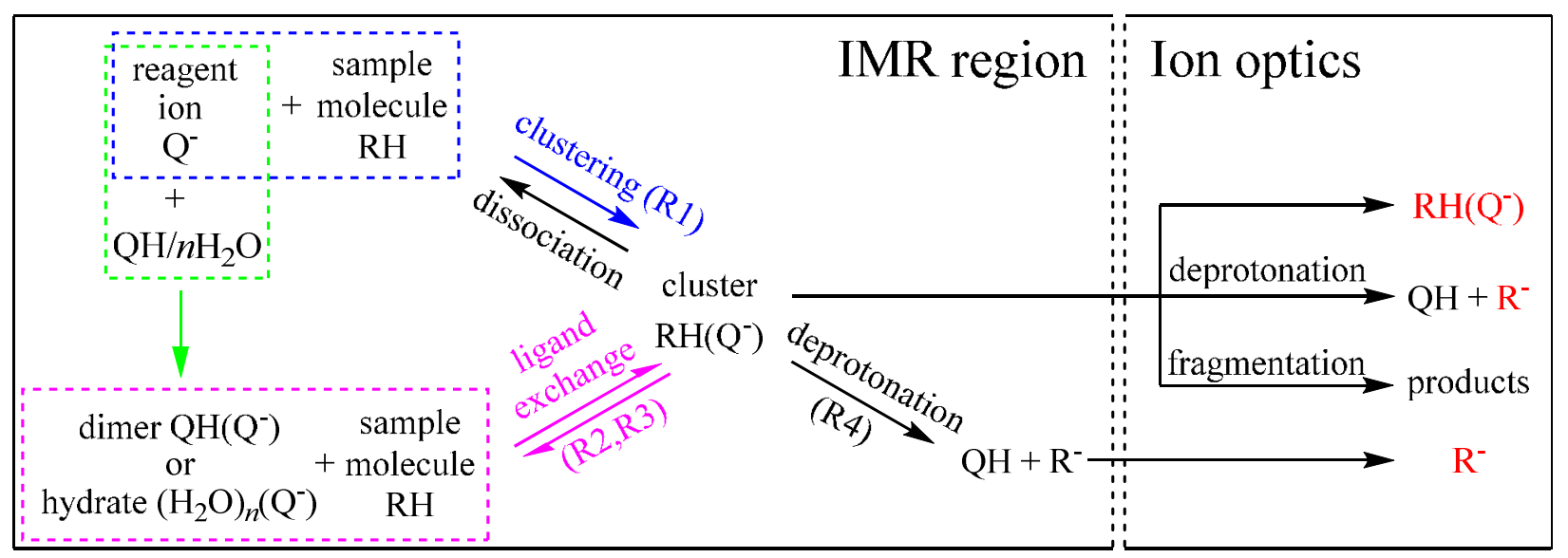


Figure 1. The different processes occurring in the ion-molecule reaction (IMR) region and the ion optics of chemical ionization instruments. The cluster and ions marked in red can be detected by the mass spectrometer.

With some combinations of reagent ions and sample molecules, reagent ions are able to ionize the sample molecule via specific chemical reactions. For instance, nitrate and acetate are able to deprotonate (R4) sulfuric acid and various acidic organic compounds, respectively, $\mathrm{H}_{2} \mathrm{O}\left(\mathrm{I}^{-}\right)$is able to dehydroxylate peroxy acids (R5), ${ }^{10,11}$ and $\mathrm{CF}_{3} \mathrm{O}^{-}$is able to ionize some sample molecules via a fluoride transfer reaction $(\mathrm{R} 6)^{12}$ :

$$
\begin{aligned}
& R H+Q^{-} \rightarrow Q H+R^{-} \\
& R(O) O O H+H_{2} O\left(I^{-}\right) \rightarrow H O I+H_{2} O+R(O) O^{-} \\
& R H+\mathrm{CF}_{3} O^{-} \rightarrow \mathrm{CF}_{2} \mathrm{O}+\mathrm{HF}\left(R^{-}\right)
\end{aligned}
$$

Nitrate has been used in measurements of autoxidation intermediates and products of monoterpenes $^{2}$ and sesquiterpenes ${ }^{13}$ after it was noticed to be selective toward highly oxidized multifunctional compounds (HOMs) containing multiple hydrogen bonding functional groups. ${ }^{14}$ These recently discovered compounds, which likely contain multiple hydroperoxide or peroxy acid groups, may play a key role in the formation of secondary organic aerosol (SOA). ${ }^{14,15}$ In addition, nitrate is the conjugate base of a strong acid, and can thus deprotonate only species that are stronger gas-phase acids than nitric acid, i.e. sulfuric acid and a very limited number of other compounds such as malonic acid. ${ }^{16}$ These two features makes nitrate an ideal reagent ion for selectively measuring highly oxidized multifunctional compounds as nitrate clusters. Acetate has been used to measure for instance formic acid, ${ }^{17}$ carboxylic acids ${ }^{18}$ atmospherically relevant inorganic acids ${ }^{19}$ and $\alpha$-pinene SOA constituents, ${ }^{20}$ as deprotonation products. Recently, acetate has also been used to detect HOMs as both clusters and deprotonation products. ${ }^{1,2,3,21}$ In addition, 
lactate $\left(\mathrm{CH}_{3} \mathrm{CH}(\mathrm{OH}) \mathrm{C}(\mathrm{O}) \mathrm{O}^{-}\right)^{2,3}$ and pyruvate $\left(\mathrm{CH}_{3} \mathrm{C}(\mathrm{O}) \mathrm{C}(\mathrm{O}) \mathrm{O}^{-}\right)^{2}$ have been used to investigate the differences in the detection efficiencies of nitrate, acetate, lactate and pyruvate. The detection efficiency of highly oxidized $\mathrm{O}_{3}$ or $\mathrm{OH}$-initiated oxidation products is similar with both nitrate and acetate, ${ }^{1,2,3}$ but there is a clear difference in detection efficiencies of less oxidized molecules, indicating that nitrate is generally only able to ionize highly oxidized species. Measurements of the intermediates of $\mathrm{OH}$-initiated $\alpha$-pinene oxidation indicate only small differences in detection efficiencies between acetate, lactate and pyruvate. $^{2}$ Measurements of $\mathrm{OH}$-initiated oxidation products of isoprene show that acetate and lactate have similar detection efficiencies, but nitrate has a much lower detection efficiency even for a sample molecule that contains two hydroxy and two hydroperoxy groups. ${ }^{3}$

Other reagent anions that have been used in atmospheric CIMS applications include $\mathrm{CF}_{3} \mathrm{O}^{-}$, $\mathrm{Br}^{-}$and $\mathrm{I}^{-} \cdot \mathrm{CF}_{3} \mathrm{O}^{-}$measurements of, for instance, inorganic acids, ${ }^{12}$ carboxylic acids, ${ }^{22}$ hydroperoxides $^{5}$ and hydroxynitrates ${ }^{23}$ have shown that, for strong inorganic acids, the primary ionization mechanism with $\mathrm{CF}_{3} \mathrm{O}^{-}$is generally fluoride transfer (R6), ${ }^{12}$ though some molecules may be detected as both fluoride transfer products and clusters. With weak acids, $\mathrm{CF}_{3} \mathrm{O}^{-}$forms clusters, but the clustering efficiency depends on the relative humidity. ${ }^{5} \mathrm{I}^{-}$has mostly been used in the measurements of small inorganic and organic molecules, such as $\mathrm{HO}_{2},{ }^{6} \mathrm{HO}_{2} \mathrm{NO}_{2}{ }^{24}$ and formic acid, ${ }^{25}$ and more recently also highly oxidized SOA constituents. ${ }^{26,27} \mathrm{Br}^{-}$was recently used for the detection of the $\mathrm{HO}_{2}$ radical. ${ }^{28}$

Chemical ionization processes have been studied by computing the formation free energies and binding enthalpies of the ion-molecule clusters. ${ }^{2,29,30,31}$ A comparison between experimental work and calculations has shown that the binding enthalpies of $\mathrm{I}^{-}$clusters correlate well with the detection efficiencies of a CIMS instrument..$^{30,32}$ The enthalpies were found to be better than free 
energies for modeling the sensitivity of the instrument toward molecules forming weakly bound ion-molecule clusters which likely undergo non-thermal fragmentation reactions in the low pressure regions of a mass spectrometer (e.g. the ion optics, see Figure 1). ${ }^{30}$ However, Gibbs free energies can be used to model the chemical ionization reactions occurring under sufficiently high pressure in the ion-molecule reaction (IMR) region of the instrument, where the clusters are efficiently collisionally stabilized by collisions with carrier gas molecules, provided that the total number of atoms in the reagent ion - sample molecule cluster is more than about $8 .{ }^{33}$ (Clusters with fewer atoms may dissociate before collisional stabilization even at high pressures, due to their low number of vibrational modes).

The formation free energies of ion-molecule clusters have revealed that acetate forms more stable clusters than nitrate with neutral molecules containing peroxy acid, ${ }^{31}$ hydroxy, hydroperoxy and carboxylic acid groups. ${ }^{2}$ The binding of the nitrate and acetate clusters of intermediates and products of cyclohexene oxidation ${ }^{31}$ is much stronger than $25 \mathrm{kcal} / \mathrm{mol}$, which is the binding strength predicted by Iyer et al. ${ }^{30}$ to correspond to the maximum sensitivity (i.e. the highest measured cps/pptv of the instrument) of an iodide based CIMS. While the precise value of this limiting binding enthalpy is instrument-dependent, this nevertheless makes it likely that the fragmentation of such clusters in the typical CIMS instruments (that do not use collisional dissociation chambers $(\mathrm{CDC})$ to break apart the weakly bound ion-molecule clusters $^{17,28}$ ) should not significantly affect the detection efficiency. Comparing computational results $^{31}$ with CIMS measurements ${ }^{1}$ on molecules forming strongly bound ion-molecule clusters indicates that the detection efficiency of the sample molecules is low when the ligand exchange reaction with the reagent ion dimer is unfavorable, and high when it is favorable. 
There are thus two different regimes that determine the main parameter affecting the detection efficiency of CIMS instruments: a kinetic regime and a thermodynamic regime. In the kinetic regime, the thermal dissociation rate of the clusters is much slower than their formation rate. This regime applies to sample molecules that form stable clusters with the reagent ions, and which have clearly favorable ligand exchange reactions with possible reagent ion clusters (e.g. dimers or hydrates). In the absence of non-thermal fragmentation, the concentration of the ionmolecule clusters mainly depends on the rate of collisions between the sample molecules and the reagent ions. Additionally, the collision rates play a larger role in the detection efficiencies if the CIMS instrument is operated as a drift tube (short interaction times) and not near the equilibrium limit like most nitrate and $\mathrm{I}^{-}$instruments. The collision rates can be estimated from the conformationally weighted dipole moments and polarizabilities of the molecules and reagent ions. ${ }^{34}$ The calculated collision rates of various atmospherically relevant organic sample molecules have been found to be within a factor of two of each other ${ }^{30}$ indicating that the detection efficiencies of molecules forming strongly bound clusters with the reagent ions should be quite similar (though the mass-dependent ion transmission efficiency of the instrument may naturally also affect the detection ${ }^{32,35}$ ). If the ion-molecule clusters are weakly bound, the thermal dissociation rate of the clusters is comparable to, or higher than, the formation rate of the clusters. In this thermodynamic regime, the effect of the collision rates on the detection efficiency of the instrument is smaller, because of the larger effect from the dissociation. Due to differences in dissociation, ligand exchange and fragmentation rates, detection efficiencies in the thermodynamic regime can vary by many orders of magnitude. Based on the model created by Iyer et $\mathrm{al},{ }^{30}$ already small differences in the cluster stabilities have a large effect on the detection efficiency when the binding enthalpy of the cluster is below $25 \mathrm{kcal} / \mathrm{mol}$. 
Our goal in this study is to compare seven negative reagent ions that are commonly used (nitrate $\left(\mathrm{NO}_{3}{ }^{-}\right)$, acetate $\left(\mathrm{CH}_{3} \mathrm{C}(\mathrm{O}) \mathrm{O}^{-}\right)$, lactate $\left(\mathrm{CH}_{3} \mathrm{CH}(\mathrm{OH}) \mathrm{C}(\mathrm{O}) \mathrm{O}^{-}\right)$, trifluoromethanolate $\left(\mathrm{CF}_{3} \mathrm{O}^{-}\right)$and iodide $\left(\mathrm{I}^{-}\right)$) or could potentially be used (trifluoroacetate $\left(\mathrm{CF}_{3} \mathrm{C}(\mathrm{O}) \mathrm{O}^{-}\right)$and bromide $\left.\left(\mathrm{Br}^{-}\right)\right)$in the gas-phase detection of oxidized organic compounds. In addition to computing the ion-molecule cluster stabilities, we investigate two known chemical reactions of these reagent ions, deprotonation with acetate and fluoride transfer with $\mathrm{CF}_{3} \mathrm{O}^{-}$. Additionally, we calculate the formation free energies and enthalpies of all the reagent ion hydrates, $\left(\mathrm{H}_{2} \mathrm{O}\right)_{n}\left(\mathrm{Q}^{-}\right)$with $n=1,2$, and 3, as well as selected hydrated ion-molecule clusters, to investigate the humidity dependence of each reagent ion.

Previously, chemical ionization with different reagent ions has been used in many studies for the detection of isoprene oxidation products. $3,36,37,38,39,40,41,42,43,44$ The oxidation of butadiene and isoprene yield similar products, ${ }^{44}$ while the butadiene products are computationally less demanding. For this reason, we use as sample molecules several possible $\mathrm{OH}$-initiated oxidation products of butadiene containing hydroxy, hydroperoxy, carbonyl and epoxy groups, which are typical moieties in the products of atmospheric oxidation of alkenes. In addition we chose three other molecules containing hydroxyl groups: glucic acid, a nitrobutanol and a nitrophenol, which could potentially be used in the calibration of chemical ionization instruments. The sample molecules used in this study are shown in Figure 2. 


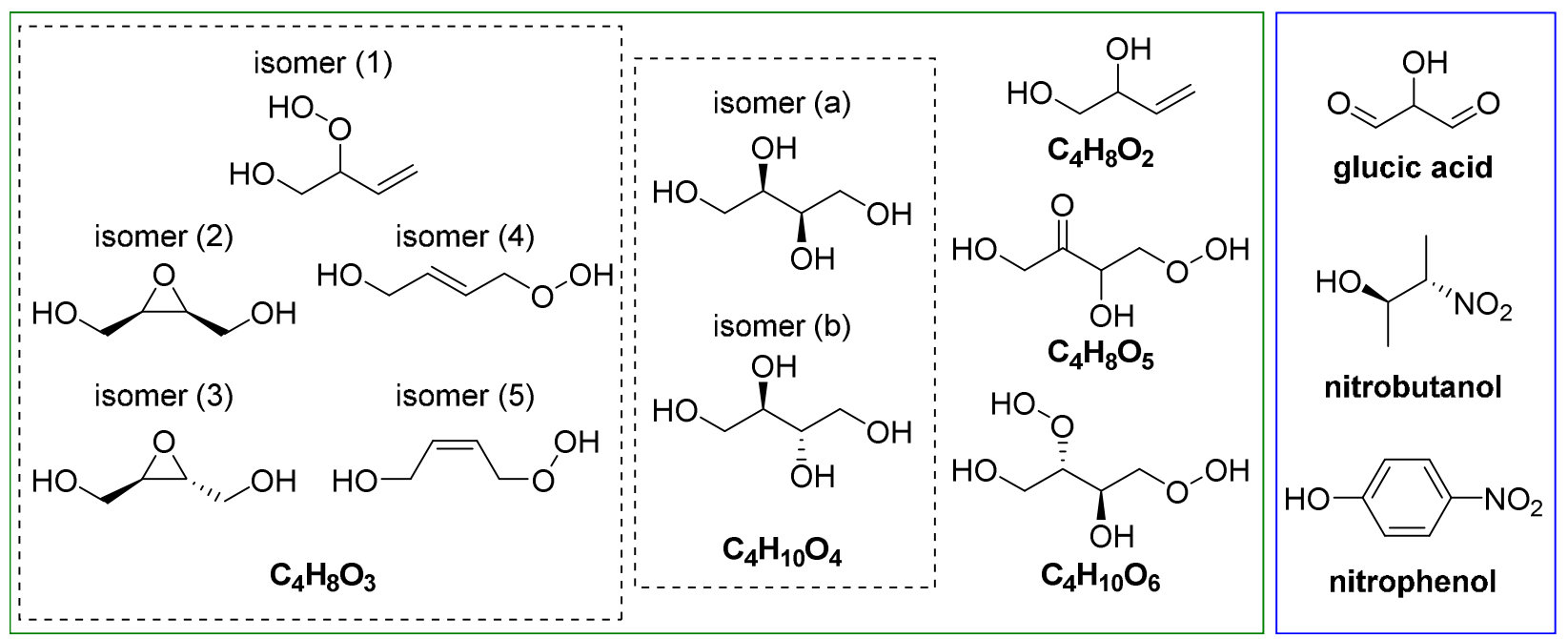

Figure 2. The sample molecules of this study.

\section{COMPUTATIONAL METHODS}

We calculated the chemical ionization reaction energies as the energy difference between the free molecules and the products, i.e. clusters, or deprotonation (R4) and fluoride transfer (R6) products. In our calculations we use the lowest free energy conformers of the molecules and clusters. To obtain the lowest energy conformers, we performed a systematic conformer search similar to our previous studies. ${ }^{4,29,31}$ The initial conformer search was done with the Spartan ' $14^{45}$ program using the molecular mechanics MMFF method and a systematic conformer sampling algorithm. Single-point energies were calculated at the B3LYP/6-31+G* level of theory and all conformers within $5 \mathrm{kcal} / \mathrm{mol}$ of the lowest electronic energy conformer were used in the following geometry optimization at the same level using Gaussian $09 .{ }^{46}$ The final geometry optimization and frequencies at the $\omega \mathrm{B} 97 \mathrm{xD} / \mathrm{aug}-\mathrm{cc}-\mathrm{pVTZ}$ level of theory (aug-ccpVTZ-PP ${ }^{47,48,49}$ basis set for Br and I) for conformers within $2 \mathrm{kcal} / \mathrm{mol}$ from the lowest B3LYP electronic energy conformer (with the ultrafine integration grid) were also calculated using Gaussian 09. 
For the final single-point electronic energies we tested three different coupled cluster approaches:

- DLPNO $_{\text {default }}:=$ DLPNO-CCSD $(\mathrm{T})^{50,51} / \operatorname{def} 2-\mathrm{QZVPP}{ }^{52}$ with the corresponding auxiliary basis set and default truncation parameters implemented in $\mathrm{ORCA}^{53}$ versions 3.0 .1 and 3.0.3.

- DLPNO $_{\text {tight }}:=$ DLPNO-CCSD(T)/def2-QZVPP with tighter truncation parameters $T_{\text {CutPNO }}=10^{-7}, T_{\text {CutPairs }}=10^{-5}$ and $T_{\text {CutMKN }}=10^{-4}, 30$ and additional effective core potentials $^{54}$ (def2-SD, def2-QZVPP and def2-QZVPP/C). Additionally in the $\mathrm{I}$ cluster calculations, we used the frozen core method with the default cutoff values of the energy window $\left(\mathrm{E}_{\mathrm{Min}}=-3 \mathrm{Ha}\right.$ and $\left.\mathrm{E}_{\mathrm{Max}}=1000 \mathrm{Ha}\right)$.

- $\quad \mathrm{F} 12:=$ ROHF-ROCCSD(T)-F12a/VDZ-F12 level of theory (VDZ-PP-F12 ${ }^{55}$ basis set for Br and I) using Molpro version $2015.1^{56}$ with gem_beta=0.9. ${ }^{57}$

To compare the different coupled cluster methods, we selected one of the small sample molecules, isomer (2) of $\mathrm{C}_{4} \mathrm{H}_{8} \mathrm{O}_{3}$, and calculated the energy corrections to the formation energies of all ion-molecule clusters, the deprotonation energy with acetate, and the fluoride transfer energy with $\mathrm{CF}_{3} \mathrm{O}^{-}$. The comparison of the different coupled cluster calculations can be found in Section S1 and Table S1 of the SI. Because of the high computational cost of the F12 calculations and the accuracy of the $\mathrm{DLPNO}_{\text {tight }}$ method compared to the more accurate F12

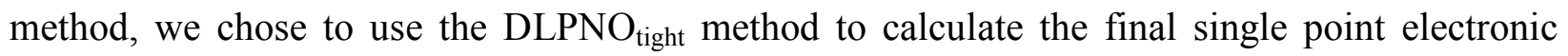
energies for the full set of the studied systems.

The conformer search of the clusters was done without any constraints between the sample molecule and the reagent ion, but other sampling methods were also tested (see Section S2, Figure S1 and Table S2 in the SI for details). In the unconstrained conformer search, Spartan '14 
does a conformer sampling (rotating over all dihedral bonds) of the sample molecule while not moving the reagent ion (which usually has only one unique conformer). The unconstrained conformer search is likely to be more reliable for the smaller and symmetrical reagent ions, because the reagent ion is able to form hydrogen bond from all angles equally well, and the orientation of the reagent ion has less effect on the sampling. The lowest-energy conformer might be missed if the orientation of the reagent ion is not optimal, and the reagent ion is not able to form hydrogen bonds with the sample molecule. Fortunately, the sample molecules form lowest free energy clusters with similar geometries with different reagent ions. ${ }^{31}$ Visually comparing the lowest free energy cluster conformers of different reagent ions can help locate lowest free energy cluster conformers that might be missed in the conformer search. For the hydrated $\mathrm{CF}_{3} \mathrm{O}^{-}$ion-molecule clusters, rotation around the $\mathrm{O}-\mathrm{H}$ bonds in the water molecules were enabled to sample more of the conformational space. The reagent ion hydrate conformers were found by manually placing water molecules around the reagent ions. While this method is not systematic, the conformational search algorithm in Spartan '14 is not suitable for conformer sampling if none of the separate molecules in the cluster have torsional angles to rotate around.

The MMFF method in Spartan '14 is not able to form hydrogen bonds with $\mathrm{I}^{-}$without using a constrained conformer sampling. In addition, the $6-31+\mathrm{G}^{*}$ basis set used in the first single-point energy calculations and the geometry optimizations is not available for I. For these reasons, instead of doing a separate conformer sampling of the $\mathrm{I}^{-}$clusters, we substituted the $\mathrm{Br}^{-}$in the B3LYP optimized $\mathrm{Br}^{-}$clusters by $\mathrm{I}^{-}$, and used these geometries as input for the higher level $\omega \mathrm{B} 97 \mathrm{xD}$ geometry optimizations and frequency calculations. Fortunately, the hydrogen bond lengths in the optimized $\mathrm{Br}^{-}$and $\mathrm{I}^{-}$clusters are similar $(<0.3 \AA$ difference $)$, so the change in the geometries should lead to only small differences in the relative energies of the conformers. 
However, slightly higher cut-offs were used for the $\mathrm{I}^{-}$cluster calculations, $6 \mathrm{kcal} / \mathrm{mol}$ and 3 $\mathrm{kcal} / \mathrm{mol}$ before the first and second geometry optimization, respectively.

\section{RESULTS AND DISCUSSION}

\section{CLUSTER STABILITIES}

Figure 3 illustrates how the formation free energies (and the formation enthalpies, in Figure S2 of the SI) of the clusters depend almost linearly on the number of oxygen atoms in the sample molecule. The number of hydrogen bonding functional groups or the type of the functional groups does not seem to significantly affect the cluster stability of these butadiene oxidation products, which all have two or more hydroxy and/or hydroperoxy functional groups.

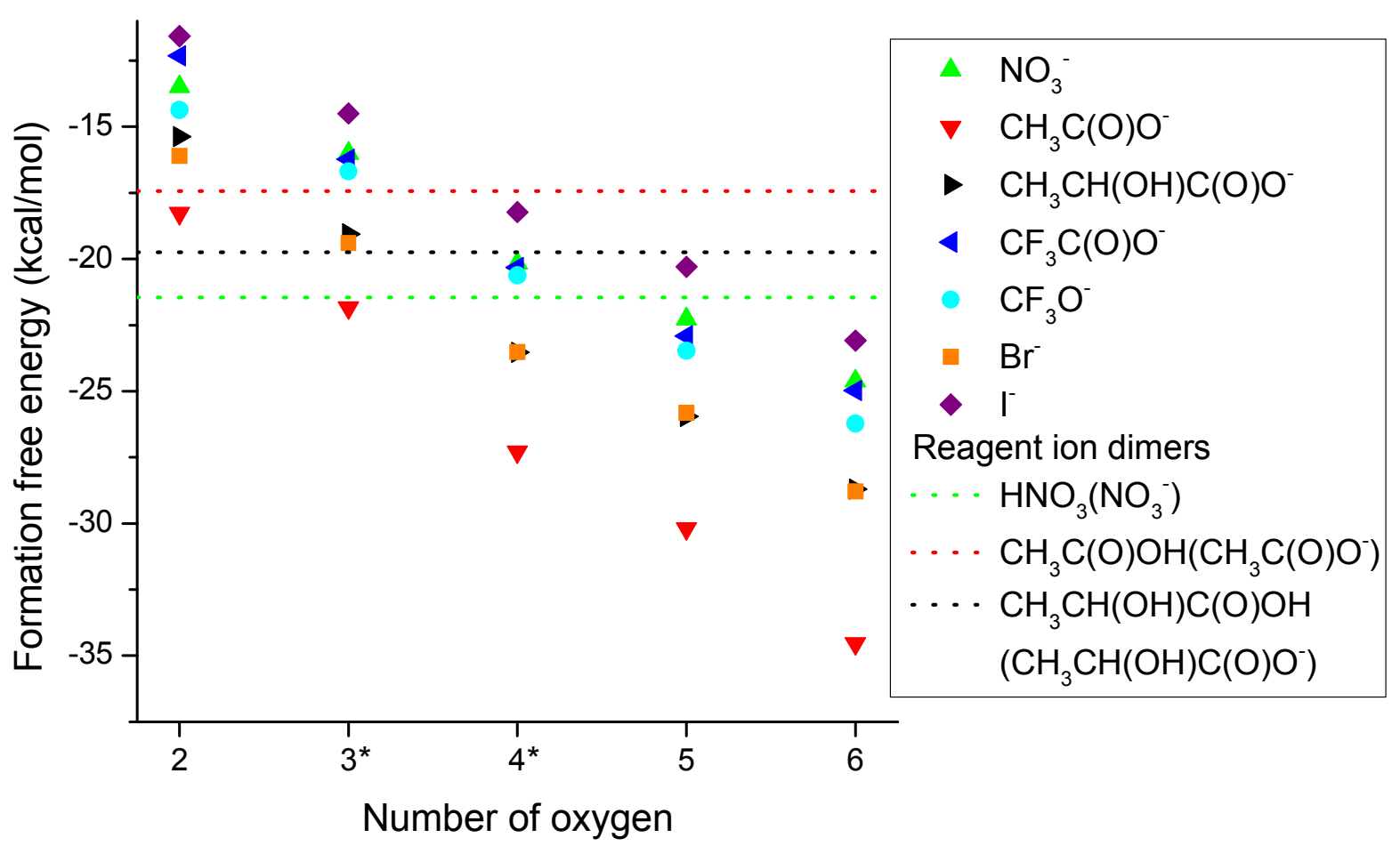

Figure 3. The formation free energies $(\Delta \mathrm{G})$ of the butadiene oxidation product clusters as a function of the number of oxygen atoms in the sample molecule, calculated at the DLPNO- 


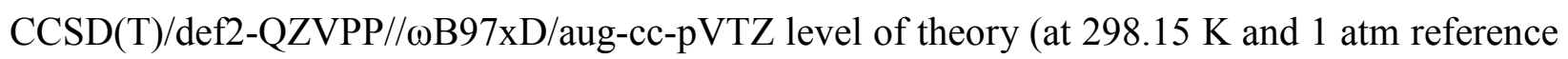
pressure). The dotted lines indicate the formation free energies of the reagent ion dimers. ${ }^{*}$ The values are the averages of the different isomers of the sample molecules.

For all of the sample molecules, the binding is weakest with $\mathrm{I}^{-}$and strongest with acetate. The formation free energies of the nitrate, $\mathrm{CF}_{3} \mathrm{C}(\mathrm{O}) \mathrm{O}^{-}$and $\mathrm{CF}_{3} \mathrm{O}^{-}$clusters are similar, but due to the strong binding of the nitric acid-nitrate dimer $\left(\mathrm{HNO}_{3}\left(\mathrm{NO}_{3}{ }^{-}\right)\right)$, only the sample molecules with five and six oxygen atoms are efficiently chemically ionized with nitrate. Lactate and $\mathrm{Br}^{-}$ clusters are less stable than the acetate clusters, but more stable than the nitrate, $\mathrm{CF}_{3} \mathrm{C}(\mathrm{O}) \mathrm{O}^{-}$and $\mathrm{CF}_{3} \mathrm{O}^{-}$clusters. All of the formation free energies $(\Delta \mathrm{G})$ and enthalpies $(\Delta \mathrm{H})$ at the DLPNO-

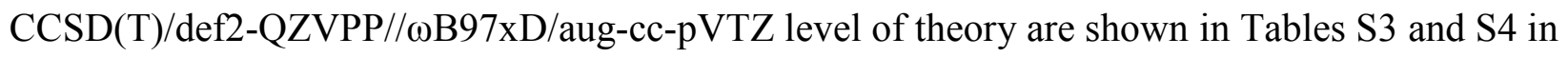
the SI.

Five of our butadiene oxidation products are different isomers of $\mathrm{C}_{4} \mathrm{H}_{8} \mathrm{O}_{3}$. Also, the two $\mathrm{C}_{4} \mathrm{H}_{10} \mathrm{O}_{4}$ products are stereoisomers. For each reagent ion, the formation free energies of these isomer clusters are within $3 \mathrm{kcal} / \mathrm{mol}$ of each other. This is slightly less than the average change in the formation free energy caused by the addition (or removal) of one oxygen atom in the sample molecule. The differences in the cluster formation free energies between the different stereoisomers are likely caused by the distance between the hydrogen bonding groups in the sample molecule. If the hydrogen bonding groups of the sample molecule are not able to form intramolecular hydrogen bonds, the energy of the free molecule is relatively higher, making the clustering more favorable. This is true for instance for isomer (4) of $\mathrm{C}_{4} \mathrm{H}_{8} \mathrm{O}_{3}$, where the two hydrogen bonding functional groups are on the opposite sides of a double bond in the carbon frame, compared to isomer (5) where the functional groups are on the same side of the double bond (Figure $4 \mathrm{a}$ and $4 \mathrm{~b}$, respectively). For isomer (b) of $\mathrm{C}_{4} \mathrm{H}_{10} \mathrm{O}_{4}$, only three of the four hydroxy 
groups are able to form intramolecular hydrogen bonds (Figure 4c), compared to isomer (a) where all of the four hydroxy groups are able to form intramolecular hydrogen bonds (Figure 4d). In contrast, if the sample molecule is not able to easily form two intermolecular hydrogen bonds to the reagent ion, and is also unable to form intramolecular hydrogen bonds with the remaining hydrogen bond donor groups while clustered to the reagent ion, the energy of the ionmolecule cluster is relatively higher, making the clustering less favorable. One example of this is isomer (3) of $\mathrm{C}_{4} \mathrm{H}_{8} \mathrm{O}_{3}$ where the distance between the two hydroxy groups is longer than that in isomer (2) (Figure 5a and 5b, respectively).

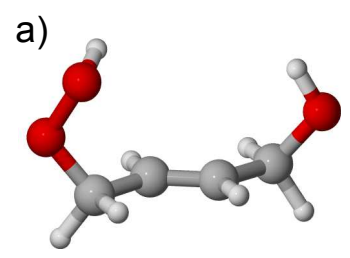

b)
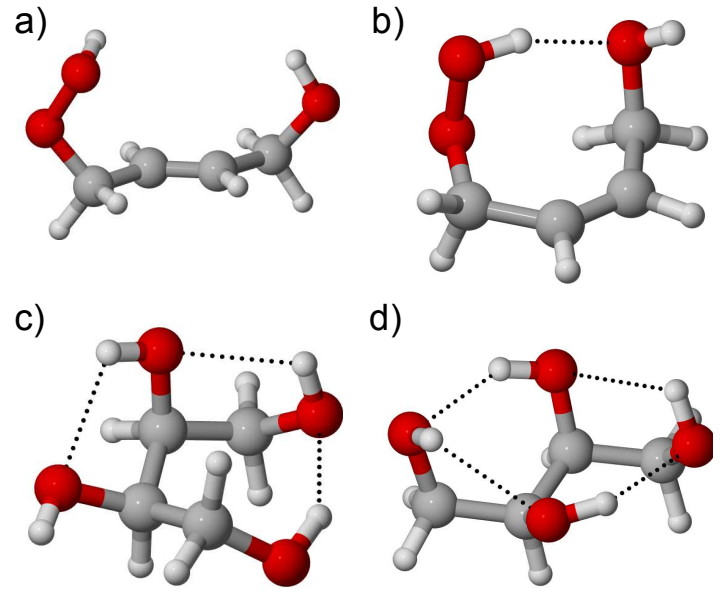

d)

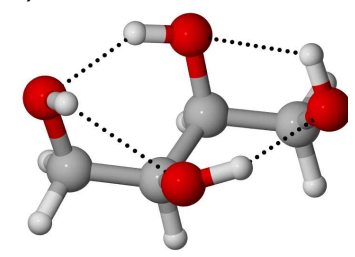

Figure 4. The lowest free energy conformers of a) isomer (4) of $\mathrm{C}_{4} \mathrm{H}_{8} \mathrm{O}_{3}$, b) isomer (5) of $\mathrm{C}_{4} \mathrm{H}_{8} \mathrm{O}_{3}, \mathrm{c}$ ) isomer (b) of $\mathrm{C}_{4} \mathrm{H}_{10} \mathrm{O}_{4}, \mathrm{~d}$ ) isomer (a) of $\mathrm{C}_{4} \mathrm{H}_{10} \mathrm{O}_{4}$. Color coding: gray = carbon, red = oxygen and white $=$ hydrogen . 
a)

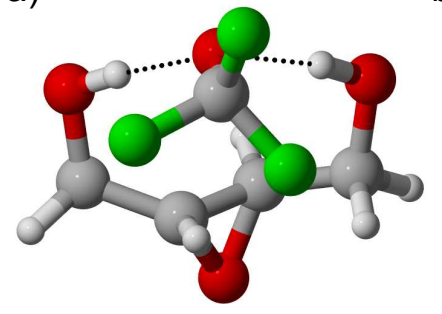

b)

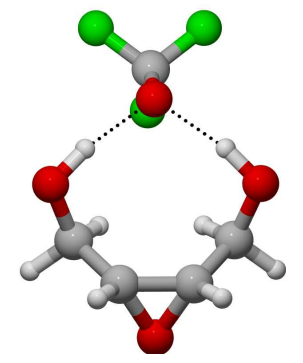

Figure 5. The lowest free energy conformers of the $\mathrm{CF}_{3} \mathrm{O}^{-}$clusters of a) isomer (3) of $\mathrm{C}_{4} \mathrm{H}_{8} \mathrm{O}_{3}$ and b) isomer (2) of $\mathrm{C}_{4} \mathrm{H}_{8} \mathrm{O}_{3}$. Color coding: gray = carbon, red = oxygen, white $=$ hydrogen and green $=$ fluorine

Most of the sample molecules form lowest free energy clusters with similar geometries with all of the reagent ions (see Table S5 in the SI). However, there are some differences in the lowest free energy conformers due to the size of the reagent ions and the length of the hydrogen bonds between the reagent ion and the sample molecule. For instance, $\mathrm{CF}_{3} \mathrm{O}^{-}$has only one efficient hydrogen bond acceptor atom (O), similar to $\mathrm{Br}^{-}$and $\mathrm{I}^{-}$, but the length of the hydrogen bonds between the sample molecules and $\mathrm{CF}_{3} \mathrm{O}^{-}$are significantly shorter than the hydrogen bond lengths formed by $\mathrm{Br}^{-}$and $\mathrm{I}^{-}$. In sample molecules where the distance between the hydrogen bonding groups is longer, the lowest free energy $\mathrm{CF}_{3} \mathrm{O}^{-}$cluster can be different from the lowest free energy clusters with other reagent ions. For the fluoride transfer reactions, we also computed the $\mathrm{F}^{-}$clusters, and some of these have different lowest free energy geometries compared to the $\mathrm{Br}^{-}$and $\mathrm{I}^{-}$clusters. Likely due to the high electronegativity of $\mathrm{F}$, in some cases the $\mathrm{F}^{-}$cluster with three intermolecular hydrogen bonds is energetically more favorable than a cluster with only two intermolecular hydrogen bonds between the sample molecule and the reagent ion. Figure $4 \mathrm{~d}$ shows an example of a sample molecule that forms different lowest free energy cluster conformers with some of the reagent ions. All except two of the ions form a similar cluster 
structure (with the nitrate cluster as an example in Figure 6a), while the clusters with $\mathrm{CF}_{3} \mathrm{O}^{-}$ (Figure $6 \mathrm{~b}$ ) and $\mathrm{F}^{-}$(Figure $6 \mathrm{c}$ ) are different.
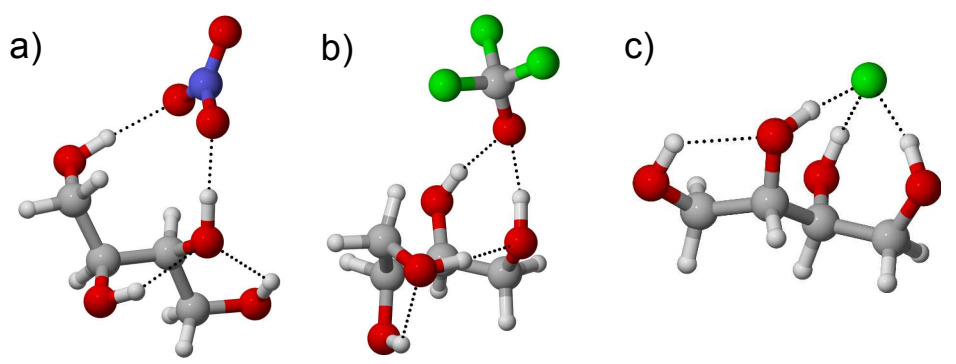

Figure 6. The lowest free energy conformers of the clusters of isomer (a) of $\mathrm{C}_{4} \mathrm{H}_{10} \mathrm{O}_{4}$ with a) $\mathrm{NO}_{3}{ }^{-}$, b) $\mathrm{CF}_{3} \mathrm{O}^{-}$and c) $\mathrm{F}^{-}$. The lowest free energy conformer of the free $\mathrm{C}_{4} \mathrm{H}_{10} \mathrm{O}_{4}$ molecule is shown in Figure 4d. Color coding: gray = carbon, red = oxygen, white $=$ hydrogen, blue $=$ nitrogen and green $=$ fluorine

\section{COMPARISON WITH ISOPRENE OXIDATION PRODUCTS}

Many of the reagent ions studied here have been used in chemical ionization measurements of

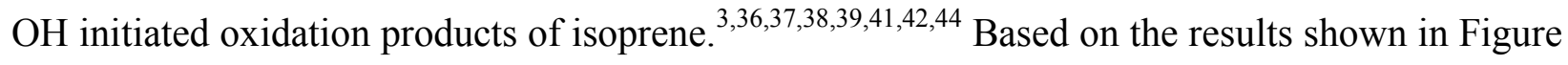
2 , the formation free energies of the clusters of a certain reagent ions with species originating from different $\mathrm{OH}$ oxidation pathways of the same parent alkene primarily depends on the number of oxygen atoms in the sample molecule. To assess the difference between the chemical ionization of isoprene and butadiene oxidation products, we have also compared the formation free energies of the ion-molecule clusters of selected butadiene oxidation products with the corresponding ion-molecule clusters of isoprene oxidation products (see Section S3 and Figure $\mathrm{S} 3$ in the SI). The formation free energies of the calculated isoprene oxidation product clusters are within $1.5 \mathrm{kcal} / \mathrm{mol}$ of the corresponding butadiene oxidation product clusters. We can thus compare the measurements of isoprene oxidation products with our calculated formation energies of the butadiene oxidation products. 
Berndt et al. ${ }^{3}$ compared the detection efficiencies of three different reagent ions, nitrate, acetate and lactate, in the measurements of $\mathrm{OH}$-initiated oxidation products of isoprene. The $\mathrm{C}_{4} \mathrm{H}_{8} \mathrm{O}_{5}$ and $\mathrm{C}_{4} \mathrm{H}_{10} \mathrm{O}_{6}$ products (Figure $7 \mathrm{a}$ and $7 \mathrm{~b}$ ) derived from butadiene oxidation have equivalent functional groups to the proposed $\mathrm{C}_{5} \mathrm{H}_{10} \mathrm{O}_{5}$ and $\mathrm{C}_{5} \mathrm{H}_{12} \mathrm{O}_{6}$ products derived from isoprene oxidation (Figure $7 \mathrm{c}$ and $7 \mathrm{~d}$ ), respectively. Berndt et al. ${ }^{3}$ also detected $\mathrm{C}_{5} \mathrm{H}_{12} \mathrm{O}_{4}$ in their measurements but the proposed structure of the molecule has two hydroxy groups and a hydroperoxy group, as opposed to the four hydroxy groups in both of our $\mathrm{C}_{4} \mathrm{H}_{10} \mathrm{O}_{4}$ isomers. The measurements ${ }^{3}$ indicate that for all three structures, acetate has the highest detection efficiency, nitrate has the lowest and lactate is between the two.<smiles>CC(CO)(OO)C(=O)CO</smiles>

Figure 7. Structures of the studied highly oxidized butadiene products, a) $\mathrm{C}_{4} \mathrm{H}_{8} \mathrm{O}_{5}$ and b) $\mathrm{C}_{4} \mathrm{H}_{10} \mathrm{O}_{6}$, and the highly oxidized isoprene products c) $\mathrm{C}_{5} \mathrm{H}_{10} \mathrm{O}_{5}$ and d) $\mathrm{C}_{5} \mathrm{H}_{12} \mathrm{O}_{6}$ proposed by Berndt et al. ${ }^{3}$

Assuming that in the measurements the sample molecules are ionized by collisions with reagent ion dimers, we can calculate the ligand exchange probabilities by calculating the probability $(p)$ of the $\mathrm{RH} \cdot \mathrm{QH}\left(\mathrm{Q}^{-}\right) \rightarrow \mathrm{QH}+\mathrm{RH}\left(\mathrm{Q}^{-}\right)$pathway, as opposed to $\mathrm{RH} \cdot \mathrm{QH}\left(\mathrm{Q}^{-}\right) \rightarrow \mathrm{RH}+$ $\mathrm{QH}\left(\mathrm{Q}^{-}\right)$, using

$$
p=\frac{e^{-\Delta G_{R H\left(Q^{-}\right) / R T}}}{e^{-\Delta G_{R H}\left(Q^{-}\right)^{/ R T}+e^{-\Delta G} Q H\left(Q^{-}\right)^{/ R T}}},
$$


where $\Delta G_{R H\left(Q^{-}\right)}$and $\Delta G_{Q H\left(Q^{-}\right)}$are the formation free energies of clusters $\mathrm{RH}\left(\mathrm{Q}^{-}\right)$and $\mathrm{QH}\left(\mathrm{Q}^{-}\right)$, respectively, $R$ is the gas constant and $T$ is temperature. The formation free energies relative to the reagent ion dimers, and the fragmentation probabilities of the butadiene oxidation products, at $298.15 \mathrm{~K}$, are shown in Table 1.

Table 1. Gibbs Free Energies of the Ligand Exchange Reactions $(\Delta \Delta \mathrm{G}$ in $\mathrm{kcal} / \mathrm{mol}) \mathrm{RH}+\mathrm{QH}\left(\mathrm{Q}^{-}\right.$ )$\rightarrow \mathrm{QH}+\mathrm{RH}\left(\mathrm{Q}^{-}\right)$and the Probabilities $(\mathrm{p})$ of the Dissociation Path $\mathrm{RH} \cdot \mathrm{QH}\left(\mathrm{Q}^{-}\right) \rightarrow \mathrm{QH}+$ $\mathrm{RH}\left(\mathrm{Q}^{-}\right)$of the Butadiene Oxidation Products, at $298.15 \mathrm{~K}$ and $1 \mathrm{~atm}$

\begin{tabular}{|c|c|c|c|c|c|c|}
\hline Reagent ion & \multicolumn{2}{|c|}{$\mathrm{NO}_{3}{ }^{-}$} & \multicolumn{2}{c|}{$\mathrm{CH}_{3} \mathrm{C}(\mathrm{O}) \mathrm{O}^{-}$} & \multicolumn{2}{c|}{$\mathrm{CH}_{3} \mathrm{CH}(\mathrm{OH}) \mathrm{C}(\mathrm{O}) \mathrm{O}^{-}$} \\
\hline Sample molecule & $\Delta \Delta \mathrm{G}$ & $\mathrm{p}$ & $\Delta \Delta \mathrm{G}$ & $\mathrm{p}$ & $\Delta \Delta \mathrm{G}$ & $\mathrm{p}$ \\
\hline $\mathrm{C}_{4} \mathrm{H}_{8} \mathrm{O}_{2}$ & 7.98 & 0.00 & -0.84 & 0.80 & 4.97 & 0.00 \\
\hline $\mathrm{C}_{4} \mathrm{H}_{8} \mathrm{O}_{3}{ }^{*}$ & 5.46 & 0.00 & -4.41 & $0.99-1.00$ & 1.29 & $0.03-0.35$ \\
\hline $\mathrm{C}_{4} \mathrm{H}_{10} \mathrm{O}_{4}{ }^{*}$ & 1.30 & $0.02-0.38$ & -9.86 & 1.00 & -3.19 & $0.97-1.00$ \\
\hline $\mathrm{C}_{4} \mathrm{H}_{8} \mathrm{O}_{5}$ & -0.81 & 0.80 & -12.76 & 1.00 & -5.61 & 1.00 \\
\hline $\mathrm{C}_{4} \mathrm{H}_{10} \mathrm{O}_{6}$ & -3.16 & 1.00 & -17.11 & 1.00 & -8.36 & 1.00 \\
\hline
\end{tabular}

* The Gibbs free energies $(\Delta \Delta G)$ are averages of the different isomers and the probabilities (p) are given as an interval if the probability is not same for all isomers.

The ligand exchange between the lactic acid-lactate dimer $\left(\mathrm{CH}_{3} \mathrm{CH}(\mathrm{OH}) \mathrm{C}(\mathrm{O}) \mathrm{OH}\left(\mathrm{CH}_{3} \mathrm{CH}(\mathrm{OH}) \mathrm{C}(\mathrm{O}) \mathrm{O}^{-}\right)\right)$and the different isomers of $\mathrm{C}_{4} \mathrm{H}_{8} \mathrm{O}_{3}$ is unfavorable on average by $1.29 \mathrm{kcal} / \mathrm{mol}$ in free energy, with ligand exchange probabilities of $0.03,0.26$, 0.06, 0.35 and 0.05 for isomers (1) - (5) of $\mathrm{C}_{4} \mathrm{H}_{8} \mathrm{O}_{3}$, respectively. Similarly with nitrate, the ligand exchange between the nitric acid-nitrate dimer and the two $\mathrm{C}_{4} \mathrm{H}_{10} \mathrm{O}_{4}$ isomers is unfavorable by on average $1.30 \mathrm{kcal} / \mathrm{mol}$, leading to ligand exchange probabilities of 0.02 and 0.38 for isomers (a) and (b), respectively. Assuming that the $\mathrm{C}_{5} \mathrm{H}_{12} \mathrm{O}_{4}\left(\mathrm{NO}_{3}{ }^{-}\right)$cluster has a formation free energy similar to the $\mathrm{C}_{4} \mathrm{H}_{10} \mathrm{O}_{4}\left(\mathrm{NO}_{3}{ }^{-}\right)$cluster, $\mathrm{C}_{5} \mathrm{H}_{12} \mathrm{O}_{4}$ likely has a low ligand 
exchange probability, which would explain why it was not detected using nitrate. ${ }^{3}$ For sample molecules with five or more oxygen atoms, the detection efficiency with lactate was found to be similar to acetate. ${ }^{3}$ Taking into account the possible differences in the binding of the isoprene and butadiene oxidation products, and the different isomers, our calculations agree well with measurements ${ }^{3}$ of the isoprene oxidation products.

\section{REAGENT ION HYDRATES}

The formation free energies of the reagent ion hydrates were calculated with up to three water molecules (Table 2). The binding of the first water molecule to the reagent ions is the strongest and the binding strength of the additional water molecules is for all reagent ions significantly weaker. The order of the formation free energies of the reagent ion hydrates is similar to that of the reagent ion - sample molecule clusters. Measured literature values of the formation free energies are also given in Table 2. The calculated formation free energies of the monohydrates are very close to the measured values, but the calculations systematically under-estimate the stability of the di- and trihydrates compared to the measurements.

We also calculated the formation free energies of the reagent ion dimer monohydrates $\left(\mathrm{H}_{2} \mathrm{O} \cdot \mathrm{QH}\left(\mathrm{Q}^{-}\right)\right)$for the reagent ions that form dimers, i.e. $Q^{-}=\mathrm{NO}_{3}^{-}, \mathrm{CH}_{3} \mathrm{C}(\mathrm{O}) \mathrm{O}^{-}$and $\mathrm{CH}_{3} \mathrm{CH}(\mathrm{OH}) \mathrm{C}(\mathrm{O}) \mathrm{O}^{-}$. Water molecules bind weakly to the reagent ion dimers, indicating that the humidity dependence using these three reagent ions should be lower than using the reagent ions that are not able to form dimers. Water binds more strongly to the acetic acid-acetate dimer than to the other two reagent ion dimers, which could lead to higher humidity dependence in the acetate measurements than in the nitrate and lactate measurements. 
Table 2. Formation Free Energies $(\Delta \mathrm{G}$ in $\mathrm{kcal} / \mathrm{mol}$ ) of the Reagent Ion Hydrates (at $298.15 \mathrm{~K}$

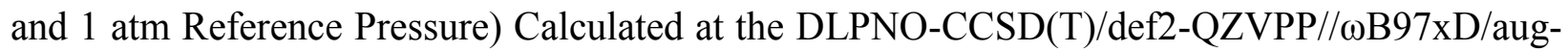
cc-pVTZ Level of Theory. Experimental Literature Values in Brackets.

\begin{tabular}{|c|c|c|c|c|}
\hline & $\begin{array}{c}\text { Reagent ion } \\
\text { monomer }+\mathrm{H}_{2} \mathrm{O}\end{array}$ & $\begin{array}{c}\text { Monohydrate } \\
\mathrm{H}_{2} \mathrm{O}\end{array}$ & Dihydrate $+\mathrm{H}_{2} \mathrm{O}$ & $\begin{array}{c}\text { Reagent ion } \\
\text { dimer }+\mathrm{H}_{2} \mathrm{O}\end{array}$ \\
\hline $\mathrm{NO}_{3}^{-}$ & $-7.41(-7.1)^{\mathrm{a}}$ & $-3.94(-5.2)^{\mathrm{a}}$ & $-1.78(-3.9)^{\mathrm{a}}$ & -1.45 \\
\hline $\mathrm{CH}_{3} \mathrm{C}(\mathrm{O}) \mathrm{O}^{-}$ & $-9.14(-9.4)^{\mathrm{a}}$ & $-4.66(-6.8)^{\mathrm{a}}$ & $-5.03(-5.2)^{\mathrm{a}}$ & -3.82 \\
\hline $\mathrm{CH}_{3} \mathrm{CH}(\mathrm{OH}) \mathrm{C}(\mathrm{O}) \mathrm{O}^{-}$ & $-7.22(-7.7)^{\mathrm{a}}$ & $-3.97(-5.3)^{\mathrm{a}}$ & -1.66 & -1.60 \\
\hline $\mathrm{CF}_{3} \mathrm{C}(\mathrm{O}) \mathrm{O}^{-}$ & $-6.32(-6.8)^{\mathrm{a}}$ & $-3.14(-4.7)^{\mathrm{a}}$ & -1.73 & - \\
\hline $\mathrm{CF}_{3} \mathrm{O}^{-}$ & $-6.76(-6.7)^{\mathrm{b}}$ & -3.32 & -1.75 & - \\
\hline $\mathrm{Br}^{-}$ & $-7.51(-7.3)^{\mathrm{c}}$ & $-3.84(-6.2)^{\mathrm{c}}$ & $-3.08(-4.7)^{\mathrm{c}}$ & - \\
\hline$\Gamma^{-}$ & $-5.55(-5.7)^{\mathrm{c}}$ & $-2.11(-4.3)^{\mathrm{c}}$ & $-1.51(-3.1)^{\mathrm{c}}$ & - \\
\hline
\end{tabular}

${ }^{\mathrm{a}} \Delta \mathrm{G}$ at $293 \mathrm{~K}$ and $1 \mathrm{~atm} .{ }^{58 \mathrm{~b}} \Delta \mathrm{G}$ at $298.15 \mathrm{~K}$ and $1 \mathrm{~atm}^{.}{ }^{7 \mathrm{c}} \Delta \mathrm{G}$ at $298.15 \mathrm{~K}$ and $1 \mathrm{~atm} .{ }^{59}$

We additionally investigated the monohydrates of the reagent ion - sample molecule clusters of the two strongest binding reagent ions, acetate and $\mathrm{Br}^{-}$. As sample molecules, we selected four butadiene oxidation products with different number of oxygen atoms to see whether the number of oxygen atoms significantly affects the humidity dependence in the measurements. The binding of the sample molecule to the reagent ion monohydrate is weaker than to the reagent ion monomer. Also, the water molecule binds to the ion-molecule cluster with less than $3 \mathrm{kcal} / \mathrm{mol}$ free energy for both of these reagent ions (Table 3), which is a weaker binding than to free $\mathrm{Br}^{-}$or to the acetate monomer or dimer. Any water molecules binding with the ion-molecule cluster are thus likely to fragment from the cluster, even with these strongly binding reagent ions. Based on these results, the addition of oxygen atoms to the sample molecule does not significantly affect the hydration of the ion-molecule clusters. 
Table 3. The Formation Free Energies of Acetate and $\mathrm{Br}^{-}$Ion-Molecule Monohydrate Clusters in

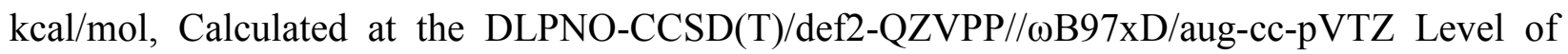
Theory

\begin{tabular}{|c|c|c|}
\hline & $\mathrm{RH}\left(\mathrm{CH}_{3} \mathrm{C}(\mathrm{O}) \mathrm{O}^{-}\right)+\mathrm{H}_{2} \mathrm{O}$ & $\mathrm{RH}\left(\mathrm{Br}^{-}\right)+\mathrm{H}_{2} \mathrm{O}$ \\
\hline isomer (4) of $\mathrm{C}_{4} \mathrm{H}_{8} \mathrm{O}_{3}$ & -2.77 & -2.02 \\
\hline isomer (a) of $\mathrm{C}_{4} \mathrm{H}_{10} \mathrm{O}_{4}$ & -2.83 & -0.11 \\
\hline $\mathrm{C}_{4} \mathrm{H}_{8} \mathrm{O}_{5}$ & -2.26 & -1.10 \\
\hline $\mathrm{C}_{4} \mathrm{H}_{10} \mathrm{O}_{6}$ & 0.55 & -0.49 \\
\hline
\end{tabular}

Because the humidity dependence in $\mathrm{CF}_{3} \mathrm{O}^{-}$measurements is significant, ${ }^{5}$ we also calculated the energies of hydrated $\mathrm{C}_{4} \mathrm{H}_{8} \mathrm{O}_{3}\left(\mathrm{CF}_{3} \mathrm{O}^{-}\right)$clusters of isomers (1), (2), (3) and (5), with up to three water molecules. Especially when measuring small sample molecules (for instance $\mathrm{H}_{2} \mathrm{O}_{2}{ }^{5}$ ) the water molecules in the hydrated reagent ion can help stabilize the forming cluster by removing excess energy. In other words, the ligand exchange reaction is less exothermic than the clustering reaction with a dry reagent ion. Comparing the free energies of adding the sample molecule to either a dry or a hydrated $\mathrm{CF}_{3} \mathrm{O}^{-}$(in Table 4) shows that the formation free energy is the lowest for the dry reagent ion and higher for the hydrated reagent ions. However, the formation of the hydrated cluster is still favorable for all of the calculated isomers and the binding of the water molecules is much weaker than the binding of the sample molecule to the cluster. If the hydrated cluster fragments in the instrument, the water molecules are thus more likely to evaporate from the cluster before the sample molecule. Of the different isomers, the decrease in the formation energy (i.e. the difference between $\mathrm{C}_{4} \mathrm{H}_{8} \mathrm{O}_{3}+\mathrm{CF}_{3} \mathrm{O}^{-}$and $\mathrm{C}_{4} \mathrm{H}_{8} \mathrm{O}_{3}+\left(\mathrm{H}_{2} \mathrm{O}\right)_{n}\left(\mathrm{CF}_{3} \mathrm{O}^{-}\right)$, for $n=1,2$ and 3) is the smallest for isomer (5) and largest for isomer (1). It is thus possible that the 
humidity dependence differs between isomers, even when the isomers have the same hydrogen bonding functional groups.

Table 4. The Formation Free Energies of Hydrated $\mathrm{C}_{4} \mathrm{H}_{8} \mathrm{O}_{3}\left(\mathrm{CF}_{3} \mathrm{O}^{-}\right)$Clusters in kcal/mol,

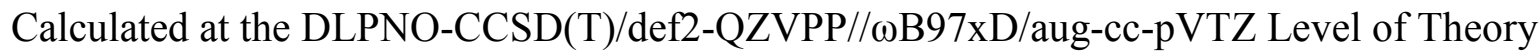

\begin{tabular}{|l|c|c|c|c|}
\hline & $\mathrm{C}_{4} \mathrm{H}_{8} \mathrm{O}_{3}+\mathrm{CF}_{3} \mathrm{O}^{-}$ & $\begin{array}{c}\mathrm{C}_{4} \mathrm{H}_{8} \mathrm{O}_{3}+ \\
\left(\mathrm{H}_{2} \mathrm{O}\right)\left(\mathrm{CF}_{3} \mathrm{O}^{-}\right)\end{array}$ & $\begin{array}{c}\mathrm{C}_{4} \mathrm{H}_{8} \mathrm{O}_{3}+ \\
\left(\mathrm{H}_{2} \mathrm{O}\right)_{2}\left(\mathrm{CF}_{3} \mathrm{O}^{-}\right)\end{array}$ & $\begin{array}{c}\mathrm{C}_{4} \mathrm{H}_{8} \mathrm{O}_{3}+ \\
\left(\mathrm{H}_{2} \mathrm{O}\right)_{3}\left(\mathrm{CF}_{3} \mathrm{O}^{-}\right)\end{array}$ \\
\hline isomer (1) & -17.17 & -11.11 & -8.59 & -7.74 \\
\hline isomer (2) & -18.08 & -13.09 & -10.21 & -8.65 \\
\hline isomer (3) & -15.58 & -10.71 & -7.43 & -7.90 \\
\hline isomer (5) & -16.06 & -12.88 & -8.51 & -10.45 \\
\hline
\end{tabular}

For the monoatomic reagent ions, the binding of the $\mathrm{Br}^{-}$clusters is on average $5 \mathrm{kcal} / \mathrm{mol}$ stronger than that of the $\mathrm{I}^{-}$clusters (see Table S4). For the trihydrate, the formation free energy difference (from the anion and three water molecules) between $\mathrm{Br}^{-}$and $\mathrm{I}^{-}$exceeds $5 \mathrm{kcal} / \mathrm{mol}$. If the relative humidity in the chemical ionization is high enough to form reagent ion hydrates with more than three waters, the detection efficiency in $\Gamma^{-}$measurements might thus be higher than the detection efficiency in $\mathrm{Br}^{-}$measurements.

\section{DEPROTONATION AND FLUORIDE TRANSFER}

To investigate the deprotonation and fluoride transfer reactions, we calculated the energies of the deprotonation reactions with acetate, $\mathrm{RH}+\mathrm{CH}_{3} \mathrm{C}(\mathrm{O}) \mathrm{O}^{-} \rightarrow \mathrm{CH}_{3} \mathrm{C}(\mathrm{O}) \mathrm{OH}+\mathrm{R}^{-}(\mathrm{R} 4)$, and the fluoride transfer reactions, $\mathrm{RH}+\mathrm{CF}_{3} \mathrm{O}^{-} \rightarrow \mathrm{CF}_{2} \mathrm{O}+\mathrm{RH}\left(\mathrm{F}^{-}\right)(\mathrm{R} 6)$ (see Table $\mathrm{S} 4$ for the energies). Comparing the deprotonation energies of the sample molecules shows that deprotonation (i.e. the gas-phase acidity) does not only depend on the number of oxygen atoms in the sample molecule $(\mathrm{RH})$, but also on the ability of the deprotonated sample molecule $\left(\mathrm{R}^{-}\right)$to form intramolecular 
hydrogen bonds. For instance, two of the $\mathrm{C}_{4} \mathrm{H}_{8} \mathrm{O}_{3}$ isomers (isomers (3) and (4) in Figure 2) have steric strain preventing the negatively charged oxygen of $\mathrm{C}_{4} \mathrm{H}_{7} \mathrm{O}_{3}{ }^{-}$from forming a hydrogen bond with the remaining hydrogen bonding functional group. From the butadiene oxidation products, only the ones that are able to form at least two intramolecular hydrogen bonds have a favorable deprotonation reaction with acetate. However, the deprotonation reaction goes through the ion-molecule cluster, and the energy difference between the cluster and the deprotonation products is high $(>20 \mathrm{kcal} / \mathrm{mol})$ for most of the products, making the deprotonation unlikely. One exception is the nitrophenol, which has the most favorable deprotonation reaction of the sample molecules studied here even though it cannot form any intramolecular hydrogen bonds. For the nitrophenol, the energy of $\mathrm{CH}_{3} \mathrm{C}(\mathrm{O}) \mathrm{OH}+\mathrm{R}^{-}$is only $9.36 \mathrm{kcal} / \mathrm{mol}$ above the ion-molecule cluster. In acetate measurements, nitrophenol has been measured as a deprotonation product with a very high sensitivity, which can be expected because of its high gas-phase acidity relative to acetic acid. ${ }^{60}$

Figure 8 shows the enthalpies of the clustering, fluoride transfer and deprotonation reactions with $\mathrm{CF}_{3} \mathrm{O}^{-}$of the nitrophenol and one of the $\mathrm{C}_{4} \mathrm{H}_{8} \mathrm{O}_{3}$ isomers (isomer (5)), as an example. In terms of the free energies, the fluoride transfer reaction is favorable for most of the molecules studied here, with the only exception being nitrobutanol, for which the reaction is unfavorable by $2.76 \mathrm{kcal} / \mathrm{mol}$. Unlike the deprotonation reaction, the reaction path of the fluoride transfer does not necessarily go through the lowest-energy ion-molecule cluster of $\mathrm{CF}_{3} \mathrm{O}^{-}$, but a less favorable cluster conformer where at least one of the fluorine atoms of $\mathrm{CF}_{3} \mathrm{O}^{-}$is binding with the hydrogen bonding groups of the sample molecule (marked with $\S$ in Figure 8). No saddle point was found between the higher energy $\mathrm{CF}_{3} \mathrm{O}^{-}$cluster and the fluoride transfer products $\mathrm{CF}_{2} \mathrm{O}+\mathrm{RH}\left(\mathrm{F}^{-}\right)$. 


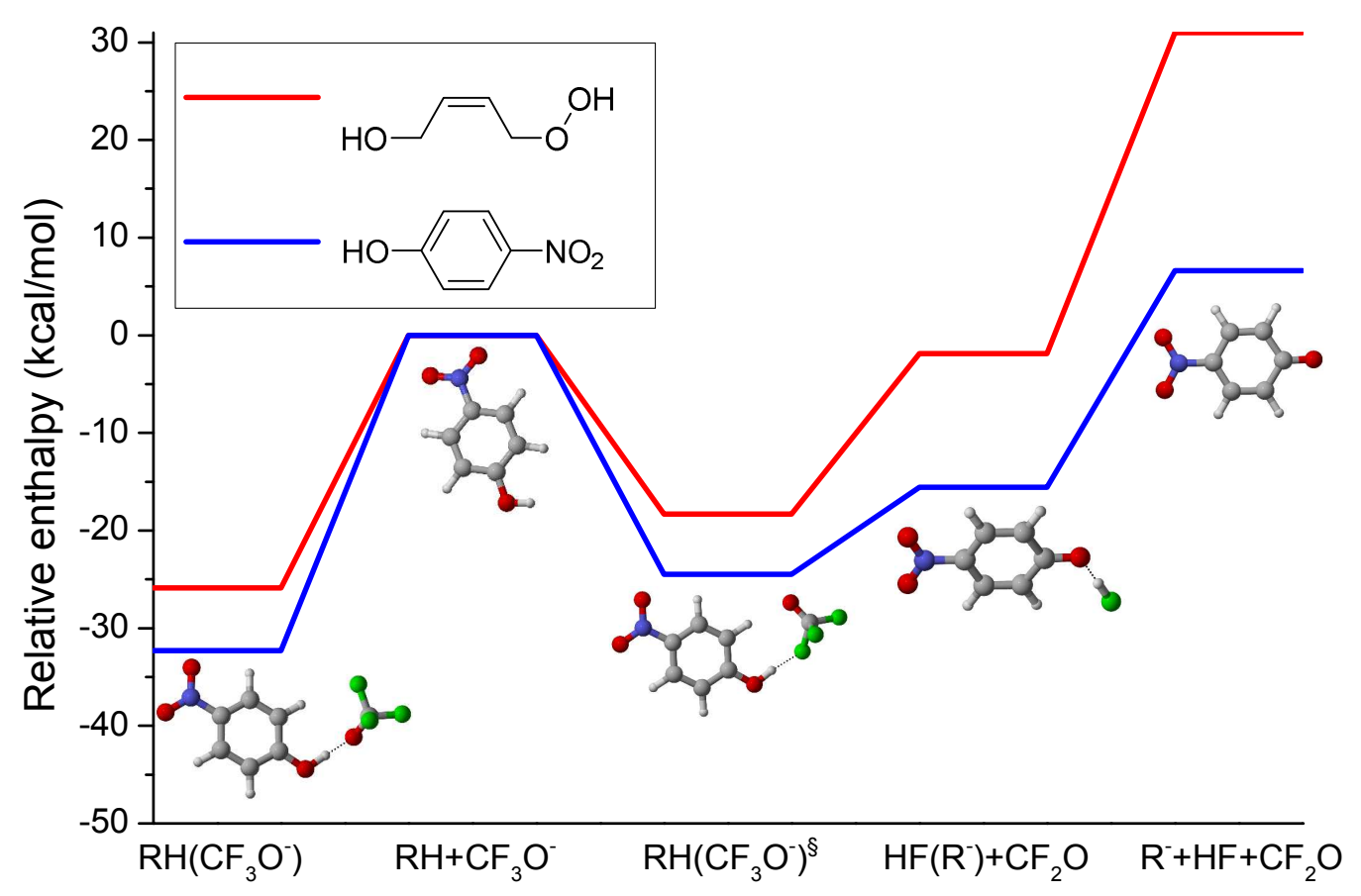

Figure 8 . The enthalpies of the stationary points in the fluoride transfer reactions of two of the

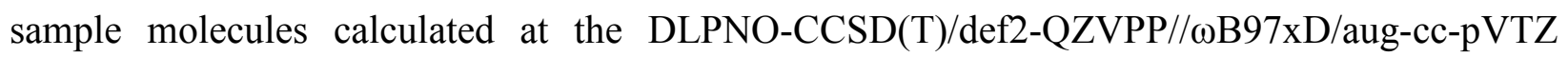
level of theory, at $298.15 \mathrm{~K}$ and $1 \mathrm{~atm}$ reference pressure. ${ }^{\S} \mathrm{The}$ higher free energy $\mathrm{CF}_{3} \mathrm{O}^{-}$cluster along the fluoride transfer reaction coordinate. Color coding of the atoms: gray $=$ carbon, red $=$ oxygen, white $=$ hydrogen, blue $=$ nitrogen, green $=$ fluorine.

With nitrophenol, the transferred fluoride forms a $\mathrm{HF}\left(\mathrm{R}^{-}\right)$cluster, and the fragmentation of this cluster into $\mathrm{HF}+\mathrm{R}^{-}$is only $13.46 \mathrm{kcal} / \mathrm{mol}$ above the free energy of the $\mathrm{HF}\left(\mathrm{R}^{-}\right)$cluster and 4.09 $\mathrm{kcal} / \mathrm{mol}$ below the free energy of $\mathrm{RH}+\mathrm{CF}_{3} \mathrm{O}^{-}$. It could thus be possible to detect some sample molecules also as deprotonation products also using $\mathrm{CF}_{3} \mathrm{O}^{-}$chemical ionization. For the other sample molecules, the free energy needed to fragment the $\mathrm{RH}\left(\mathrm{F}^{-}\right)$clusters into $\mathrm{HF}+\mathrm{R}^{-}$is higher (16.44 kcal for $\mathrm{C}_{4} \mathrm{H}_{8} \mathrm{O}_{5}, 18.06 \mathrm{kcal} / \mathrm{mol}$ for $\mathrm{C}_{4} \mathrm{H}_{10} \mathrm{O}_{6}$ and $>20 \mathrm{kcal} / \mathrm{mol}$ for the other sample molecules). 


\section{CONCLUSIONS}

We found that the binding of CIMS reagent anions to different organic sample molecules originating from the oxidation of butadiene depends primarily on the number of oxygen atoms in the sample molecule, at least when the hydrogen bonding groups of the sample molecule are hydroxy or hydroperoxy functional groups, and when the sample molecule is able to form at least two hydrogen bonds to the reagent ion. In the lowest free energy conformers of the ion-molecule clusters studied here, the reagent ions always form precisely two hydrogen bonds with the sample molecule, which explains why the number of hydrogen bond donating functional groups in the sample molecules is not in itself significant as long as it is equal to or greater than two. However, the addition of oxygen atoms to the sample molecule polarizes the functional groups that are binding with the reagent ion, making the hydrogen bonds stronger. The variation between binding strengths to a certain reagent ion of structural isomers or stereoisomers with the same elemental composition is slightly less than the effect of one additional oxygen atom. If these results apply also to larger highly oxidized multifunctional organic compounds in the atmosphere, the interpretation of CIMS measurements can be greatly simplified: the detection efficiency (for a certain reagent ion) can then be assumed to depend primarily on the number of oxygen atoms, with the precise chemical structure (e.g. the number and location of hydrogenbonding functional groups beyond a minimum of two) playing a lesser role. However, quantitatively accurate predictions of detection efficiencies in the thermodynamic regime are not possible yet due to the uncertainties in the calculations, as can be seen from the differences in the measured ${ }^{33}$ and predicted ${ }^{30}$ sensitivities of several oxidized organic compounds.

A previous study modeling the sensitivity of an iodide CIMS found that sample molecules that were measured at the maximum sensitivity for the specific CIMS instrument (19-22 $\mathrm{cps}^{-\mathrm{pptv}^{27}}$ ) 
have binding enthalpies to iodide higher than about $25 \mathrm{kcal} / \mathrm{mol} .^{27,30}$ Of the sample molecules studied here, only isomer (b) of $\mathrm{C}_{4} \mathrm{H}_{10} \mathrm{O}_{4}, \mathrm{C}_{4} \mathrm{H}_{8} \mathrm{O}_{5}, \mathrm{C}_{4} \mathrm{H}_{10} \mathrm{O}_{6}$ and nitrophenol have binding enthalpies with iodide higher than $25 \mathrm{kcal} / \mathrm{mol}$, which means that they could be detected at the maximum sensitivity. The binding enthalpies of the other sample molecules to $\mathrm{I}^{-}$vary from 19 $\mathrm{kcal} / \mathrm{mol}$ of glucic acid to $24 \mathrm{kcal} / \mathrm{mol}$ of isomer (2) of $\mathrm{C}_{4} \mathrm{H}_{8} \mathrm{O}_{3}$.

Nitrate, acetate and lactate can form stable reagent ion dimers, which means that the chemical ionization happens mainly via a ligand exchange reaction. Using these three reagent ions, the binding of the reagent ion to the sample molecule needs to be stronger than to nitric, acetic and lactic acid, respectively, to obtain a significant signal of the target molecule. For the reagent ions that do not form dimers, the ligand exchange can happen between the sample molecule and a reagent ion hydrate. For all of the sample molecules studied here, the calculated ligand exchange reaction with the reagent ion hydrates is favorable at least up to a trihydrate. The humidity dependence is likely higher for target molecules that form less stable clusters with the reagent ions. The humidity dependence may also vary more with the exact chemical structure of the target molecule than the binding to the unhydrated reagent ion. The formation free energies of the reagent ion dimer monohydrates are much higher than the formation free energies of the reagent ion monomer monohydrates, especially for nitrate and lactate. This means that there is a trade-off between the strongly binding reagent ion dimers of nitrate, lactate and acetate (leading to lower detection efficiencies) and reagent ion hydrate formation (leading to a stronger humidity dependence).

Comparing nitrate, acetate and lactate, the binding is the strongest with acetate and the weakest with nitrate, with lactate in between. Also the binding strength of the lactic acid-lactate dimer is between that of the reagent ion dimers of nitrate and acetate. The detection efficiency with 
lactate should thus be between the detection efficiencies of nitrate and acetate. These conclusions agree with the nitrate, acetate and lactate chemical ionization measurements of isoprene oxidation products. $^{3}$

Some reagent ions are selective toward specific groups of molecules due to chemical reactions such as deprotonation or fluoride transfer. For instance, acetate is able to deprotonate molecules that are more acidic than acetic acid. However, for almost all of the sample molecules studied here, deprotonation by acetate is not favorable. In addition, $\mathrm{CF}_{3} \mathrm{O}^{-}$is able to ionize some sample molecules through fluoride transfer. This reaction is possible for most of the sample molecules studied here. Nevertheless, the formation of the $\mathrm{RH}\left(\mathrm{CF}_{3} \mathrm{O}^{-}\right)$cluster is always more favorable than the fluoride transfer. Based on our calculations, $\mathrm{CF}_{3} \mathrm{C}(\mathrm{O}) \mathrm{O}^{-}$could be used in chemical ionization measurements of oxidized organic compounds with sensitivities similar to $\mathrm{CF}_{3} \mathrm{O}^{-}$, but without interference from fluoride transfer reactions. Comparing the two monoatomic reagent ions, $\mathrm{Br}^{-}$and $\mathrm{I}^{-}$, shows that at low humidities, $\mathrm{Br}^{-}$could have a higher sensitivity than $\mathrm{I}^{-}$ measuring oxidized organic compounds but at higher humidities the sensitivities of $\mathrm{Br}^{-}$and $\mathrm{I}^{-}$are likely to be similar.

\section{ASSOCIATED CONTENT}

Supporting Information is available free of charge on the ACS Publications website at DOI:

Section S1: Coupled cluster comparison. Section S2: Conformer search of the clusters. Tables S3 and S4: The electronic energies, Gibbs free energy corrections and enthalpy corrections of the neutral molecules, anions and clusters, and formation free energies and enthalpies of the clusters. Figure S2: The formation enthalpies of the butadiene oxidation product clusters as a function of the number of oxygen atoms in the sample molecule. Table S5: The lowest free energy clusters. 
Section S3: Comparison between butadiene and isoprene products. Gaussian log files and ORCA out files.

\section{AUTHOR INFORMATION}

Corresponding Author

*E-mail: theo.kurten@helsinki.fi. Tel: +358 505260123.

\section{Author Contributions}

The manuscript was written through contributions of all authors. All authors have given approval to the final version of the manuscript.

\section{ACKNOWLEDGMENT}

We thank John Crounse for helpful discussions. We thank the Academy of Finland (Grants 266388 and 299574) for funding, and CSC-IT Center for Science in Espoo, Finland, and University of Copenhagen for computing time. POW thanks the University of Copenhagen for hosting his sabbatical and funding from NASA via grant NNX14AP46G- $A C C D A M$.

\section{REFERENCES}

(1) Berndt, T.; Richters, S.; Kaethner, R.; Voigtländer, J.; Stratmann, F.; Sipilä, M.; Kulmala, M.; Herrmann, H. Gas-Phase Ozonolysis of Cycloalkenes: Formation of Highly Oxidized $\mathrm{RO}_{2}$ Radicals and Their Reactions with $\mathrm{NO}, \mathrm{NO}_{2}, \mathrm{SO}_{2}$, and Other $\mathrm{RO}_{2}$ Radicals. J. Phys. Chem. A 2015, 119, 10336-10348. 
(2) Berndt, T.; Richters, S.; Jokinen, T.; Hyttinen, N.; Kurtén, T.; Otkjær, R. V.; Kjaergaard, H. G.; Stratmann, F.; Herrmann, H.; Sipilä, M.; et al. Hydroxyl Radical-Induced Formation of Highly Oxidized Organic Compounds. Nat. Commun. 2016, 7, 13677.

(3) Berndt, T.; Herrmann, H.; Sipilä, M.; Kulmala, M. Highly Oxidized Second-Generation Products from the Gas-Phase Reaction of OH Radicals with Isoprene. J. Phys. Chem. A 2016, 120, 10150-10159.

(4) Rissanen, M. P.; Kurtén, T.; Sipilä, M.; Thornton, J. A.; Kangasluoma, J.; Sarnela, N.; Junninen, H.; Jørgensen, S.; Schallhart, S.; Kajos, M. K.; et al. The Formation of Highly Oxidized Multifunctional Products in the Ozonolysis of Cyclohexene. J. Am. Chem. Soc. 2014, $136,15596-15606$.

(5) Crounse, J. D.; McKinney, K. A.; Kwan, A. J.; Wennberg, P. O. Measurement of GasPhase Hydroperoxides by Chemical Ionization Mass Spectrometry. Anal. Chem. 2006, 78, 67266732.

(6) Iyer, S.; He, X.; Hyttinen, N.; Kurtén, T.; Rissanen, M. Computational and Experimental Investigation of the Detection of $\mathrm{HO}_{2}$ Radical and the Products of Its Reaction with Cyclohexene Ozonolysis Derived $\mathrm{RO}_{2}$ Radicals by an Iodide-Based Chemical Ionization Mass Spectrometer. J. Phys. Chem. A 2017, 121, 6778-6789.

(7) Amelynck, C.; Van Bavel, A.-M.; Schoon, N.; Arijs, E. Gas Phase Reactions of $\mathrm{CF}_{3} \mathrm{O}^{-}$and $\mathrm{CF}_{3} \mathrm{O}^{-} \cdot \mathrm{H}_{2} \mathrm{O}$ and Their Relevance to the Detection of Stratospheric HCl. Int. J. Mass. Spectrom. 2000, 202, 207-216. 
(8) Inomata, S.; Hirokawa, J. Non-radioactive Chemical Ionization Mass Spectrometry Using Acetic Acid-Acetate Cluster as a Reagent Ion for the Real-time Measurement of Acids and Hydroperoxides. Chem. Lett. 2017, 46, 38-41.

(9) Brophy, P.; Farmer, D. K. Clustering, Methodology, and Mechanistic Insight into Acetate Chemical Ionization Using High-Resolution Time-of-Flight Mass Spectrometry. Atmos. Meas. Tech. 2016, 9, 3969-3986.

(10) Mielke, L. H.; Osthoff, H. D. On Quantitative Measurements of Peroxycarboxylic Nitric Anhydride Mixing Ratios by Thermal Dissociation Chemical Ionization Mass Spectrometry. Int. J. Mass Spectrom. 2012, 310, 1-9.

(11) Furgeson, A.; Mielke, L. H.; Paul, D.; Osthoff, H. D. A Photochemical Source of Peroxypropionic and Peroxyisobutanoic Nitric Anhydride. Atmos. Environ. 2011, 45, 5025-5032.

(12) Huey, L. G.; Villalta, P. W.; Dunlea, E. J.; Hanson, D. R.; Howard, C. J. Reactions of $\mathrm{CF}_{3} \mathrm{O}^{-}$with Atmospheric Trace Gases. J. Phys. Chem. 1996, 100, 190-194.

(13) Richters, S.; Herrmann, H.; Berndt, T. Different Pathways of the Formation of Highly Oxidized Multifunctional Organic Compounds (HOMs) from the Gas-Phase Ozonolysis of $\beta$ Caryophyllene. Atmos. Chem. Phys. 2016, 16, 9831-9845.

(14) Ehn, M.; Thornton, J. A.; Kleist, E.; Sipilä, M.; Junninen, H.; Pullinen, I.; Springer, M.; Rubach, F.; Tillmann, R.; Lee, B.; et al. A Large Source of Low-Volatility Secondary Organic Aerosol. Nature 2014, 506, 476-479. 
(15) Mutzel, A.; Poulain, L.; Berndt, T.; Iinuma, Y.; Rodigast, M.; Böge, O.; Richters, S.; Spindler, G.; Sipilä, M.; Jokinen, T.; et al. Highly Oxidized Multifunctional Organic Compounds Observed in Tropospheric Particles: A Field and Laboratory Study. Environ. Sci. Technol. 2015, 49, 7754-7761.

(16) Ehn, M.; Junninen, H.; Petäjä, T.; Kurtén, T.; Kerminen, V.-M.; Schobesberger, S.; Manninen, H. E.; Ortega, I. K.; Vehkamäki, H.; Kulmala, M.; et al. Composition and Temporal Behavior of Ambient Ions in the Boreal Forest. Atmos. Chem. Phys. 2010, 10, 8513-8530.

(17) Bertram, T. H.; Kimmel, J. R.; Crisp, T. A.; Ryder, O. S.; Yatavelli, R. L. N.; Thornton, J. A.; Cubison, M. J.; Gonin, M.; Worsnop, D. R. A Field-Deployable, Chemical Ionization Timeof-Flight Mass Spectrometer. Atmos. Meas. Tech. 2011, 4, 1471-1479.

(18) Veres, P.; Roberts, J. M.; Warneke, C.; Welsh-Bon, D.; Zahniser, M.; Herndon, S.; Fall, R.; de Gouw, J. Development of Negative-Ion Proton-Transfer Chemical-Ionization Mass Spectrometry (NI-PT-CIMS) for the Measurement of Gas-Phase Organic Acids in the Atmosphere. Int. J. Mass Spectrom. 2008, 274, 48-55.

(19) Roberts, J. M.; Veres, P.; Warneke, C.; Neuman, J. A.; Washenfelder, R. A.; Brown, S. S.; Baasandorj, M.; Burkholder, J. B.; Burling, I. R.; Johnson, T. J.; et al. Measurement of HONO, HNCO, and Other Inorganic Acids by Negative-Ion Proton-Transfer Chemical-Ionization Mass Spectrometry (NI-PT-CIMS): Application to Biomass Burning Emissions. Atmos. Meas. Tech. 2010, 3, 981-990.

(20) Lopez-Hilfiker, F. D.; Mohr, C.; Ehn, M.; Rubach, F.; Kleist, E.; Wildt, J.; Mentel, Th. F.; Carrasquillo, A. J.; Daumit, K. E.; Hunter, J. F.; et al. Phase Partitioning and Volatility of 
Secondary Organic Aerosol Components Formed from $\alpha$-Pinene Ozonolysis and OH Oxidation: the Importance of Accretion Products and Other Low Volatility Compounds. Atmos. Chem. Phys. 2015, 15, 7765-7776.

(21) Richters, S.; Herrmann, H.; Berndt, T. Highly Oxidized $\mathrm{RO}_{2}$ Radicals and Consecutive Products from the Ozonolysis of Three Sesquiterpenes. Environ. Sci. Technol. 2016, 50, 23542362.

(22) Amelynck, C.; Schoon, N.; Arijs, E. Gas Phase Reactions of $\mathrm{CF}_{3} \mathrm{O}^{-}$and $\mathrm{CF}_{3} \mathrm{O}^{-} \cdot \mathrm{H}_{2} \mathrm{O}$ with Nitric, Formic, and Acetic Acid. Int. J. Mass. Spectrom. 2000, 203, 165-175.

(23) Crounse, J. D.; Paulot, F.; Kjaergaard, H. G.; Wennberg, P. O. Peroxy Radical Isomerization in the Oxidation of Isoprene. Phys. Chem. Chem. Phys. 2011, 13, 13607-13613.

(24) Veres, P. R.; Roberts, J. M.; Wild, R. J.; Edwards, P. W.; Brown, S. S.; Bates, T. S.; Quinn, P. K.; Johnson, J. E.; Zamora, R. R.; de Gouw, J. Peroxynitric Acid $\left(\mathrm{HO}_{2} \mathrm{NO}_{2}\right)$ Measurements during the UBWOS 2013 and 2014 Studies Using Iodide Ion Chemical Ionization Mass Spectrometry. Atmos. Chem. Phys. 2015, 15, 8101-8114.

(25) Le Breton, M.; McGillen, M. R.; Muller, J. B. A.; Bacak, A.; Shallcross, D. E.; Xiao, P.; Huey, L. G.; Tanner, D.; Coe, H.; Percival, C. J. Airborne Observations of Formic Acid Using a Chemical Ionization Mass Spectrometer. Atmos. Meas. Tech. 2012, 5, 3029-3039.

(26) Aljawhary, D.; Lee, A. K. Y.; Abbatt, J. P. D. High-Resolution Chemical Ionization Mass Spectrometry (ToF-CIMS): Application to Study SOA Composition and Processing. Atmos. Meas. Tech. 2013, 6, 3211-3224. 
(27) Lopez-Hilfiker, F. D.; Iyer, S.; Mohr, C.; Lee, B. H.; D’Ambro, E. L.; Kurtén, T.; Thornton, J. A. Constraining the Sensitivity of Iodide Adduct Chemical Ionization Mass Spectrometry to Multifunctional Organic Molecules Using the Collision Limit and Thermodynamic Stability of Iodide Ion Adducts. Atmos. Meas. Tech. 2016, 9, 1505-1512.

(28) Sanchez, J.; Tanner, D. J.; Chen, D.; Huey, L. G.; Ng, N. N. A New Technique for the Direct Detection of $\mathrm{HO}_{2}$ Radical Using Bromide Chemical Ionization Mass Spectrometry (BrCIMS): Initial Characterization. Atmos. Meas. Tech. 2016, 9, 3851-3861.

(29) Hyttinen, N.; Kupiainen-Määttä, O.; Rissanen, M. P.; Muuronen, M.; Ehn, M.; Kurtén, T. Modeling the Charging of Highly Oxidized Ozonolysis Products Using Nitrate-Based Chemical Ionization. J. Phys. Chem. A 2015, 119, 6339-6345.

(30) Iyer, S.; Lopez-Hilfiker, F.; Lee. B. H.; Thornton, J. A.; Kurtén, T. Modeling the Detection of Organic and Inorganic Compounds Using Iodide-Based Chemical Ionization. $J$. Phys. Chem. A 2016, 120, 576-587.

(31) Hyttinen, N.; Rissanen, M. P.; Kurtén, T. Computational Comparison of Acetate and Nitrate Chemical Ionization of Highly Oxidized Cyclohexene Ozonolysis Intermediates and Products. J. Phys. Chem. A 2017, 121, 2172-2179.

(32) Lopez-Hilfiker, F. D.; Iyer, S.; Mohr, C.; Lee, B. H.; D'Ambro, E. L.; Kurtén, T.; Thornton, J. A. Constraining the Sensitivity of Iodide Adduct Chemical Ionization Mass Spectrometry to Multifunctional Organic Molecules Using the Collision Limit and Thermodynamic Stability of Iodide Ion Adducts. Atmos. Meas. Tech. 2016, 9, 1505-1512. 
(33) Lee, B. H.; Lopez-Hilfiker, F. D.; Mohr, C.; Kurtén, T.; Worsnop, D. R.; Thornton, J. A. An Iodide-Adduct High-Resolution Time-of-Flight Chemical-Ionization Mass Spectrometer: Application to Atmospheric Inorganic and Organic Compounds. Environ. Sci. Technol. 2014, 48, 6309-6317.

(34) Garden, A. L.; Paulot, F.; Crounse, J. D.; Maxwell-Cameron, I. J.; Wennberg, P. O.; Kjaergaard, H. G. Calculation of Conformationally Weighted Dipole Moments Useful in IonMolecule Collision Rate Estimates. Chem. Phys. Letters 2009, 474, 45-50.

(35) Heinritzi, M.; Simon, M.; Steiner, G.; Wagner, A. C.; Kürten, A.; Hansel, A.; Curtius, J. Characterization of the Mass-Dependent Transmission Efficiency of a CIMS. Atmos. Meas. Tech. 2016, 9, 1449-1460.

(36) Liu, J.; D’Ambro, E. L.; Lee, B. H.; Lopez-Hilfiker, F. D.; Zaveri, R. A.; Rivera-Rios, J. C.; Keutsch, F. N.; Iyer, S.; Kurtén, T.; Zhang, Z.; et al. Efficient Isoprene Secondary Organic Aerosol Formation from a Non-IEPOX Pathway. Environ. Sci. Technol. 2016, 50, 9872-9880.

(37) Krechmer, J. E.; Coggon, M. M.; Massoli, P.; Nguyen, T. B.; Crounse, J. D.; Hu, W.; Day, D. A.; Tyndall, G. S.; Henze, D. K.; Rivera-Rios, J. C.; et al. Formation of Low Volatility Organic Compounds and Secondary Organic Aerosol from Isoprene Hydroxyhydroperoxide Low-NO Oxidation. Environ. Sci. Technol. 2015, 49, 10330-10339.

(38) Budisulistiorini, S. H.; Li, X.; Bairai, S. T.; Renfro, J.; Liu, Y.; Liu, Y. J.; McKinney, K. A.; Martin, S. T.; McNeill, V. F.; Pye, H. O. T.; et al. Examining the Effects of Anthropogenic Emissions on Isoprene-Derived Secondary Organic Aerosol Formation during the 2013 Southern 
Oxidant and Aerosol Study (SOAS) at the Look Rock, Tennessee Ground Site. Atmos. Chem. Phys. 2015, 15, 8871-8888.

(39) D’Ambro, E. L.; Lee, B. H.; Liu, J.; Shilling, J. E.; Gaston, C. J.; Lopez-Hilfiker, F. D.; Schobesberger, S.; Zaveri, R. A.; Mohr, C.; Lutz, A.; et al. Molecular Composition and Volatility of Isoprene Photochemical Oxidation Secondary Organic Aerosol under Low- and High-NO Conditions. Atmos. Chem. Phys. 2017, 17, 159-174.

(40) Lambe, A.; Massoli, P.; Zhang, X.; Canagaratna, M.; Nowak, J.; Daube, C.; Yan, C.; Nie, W.; Onasch, T.; Jayne, J.; et al. Controlled Nitric Oxide Production via $\mathrm{O}\left({ }^{1} \mathrm{D}\right)+\mathrm{N}_{2} \mathrm{O}$ Reactions for Use in Oxidation Flow Reactor Studies. Atmos. Meas. Tech. 2017, 10, 2283-2298.

(41) Crounse, J. D.; Paulot, F.; Kjaergaard, H. G.; Wennberg, P. O. Peroxy Radical Isomerization in the Oxidation of Isoprene. Phys. Chem. Chem. Phys. 2011, 13, 13607-13613.

(42) Bates, K. H.; Crounse, J. D.; St. Clair, J. M.; Bennett, N. B.; Nguyen, T. B.; Seinfeld, J. H.; Stoltz, B. M.; Wennberg, P. O. Gas Phase Production and Loss of Isoprene Epoxydiols. J. Phys. Chem. A 2014, 118, 1237-1246.

(43) Schwantes, R. H.; Teng, A. P.; Nguyen, T. B.; Coggon, M. M.; Crounse, J. D.; St. Clair, J. M.; Zhang, X.; Schilling, K. A.; Seinfeld, J. H.; Wennberg, P. O. Isoprene $\mathrm{NO}_{3}$ Oxidation Products from the $\mathrm{RO}_{2}+\mathrm{HO}_{2}$ Pathway. J. Phys. Chem. A 2015, 119, 10158-10171.

(44) Teng, A. P.; Crounse, J. D.; Wennberg, P. O. Isoprene Peroxy Radical Dynamics. J. Am. Chem. Soc. 2017, 139, 5367-5377.

(45) Spartan '14; Wavefunction, Inc.: Irvine, CA, 2014. 
(46) Frisch, M. J.; Trucks, G. W.; Schlegel, H. B.; Scuseria, G. E.; Robb, M. A.; Cheeseman, J. R.; Scalmani, G.; Barone, V.; Mennucci, B.; Petersson, G. A.; et al. Gaussian 09, Revision D.01; Gaussian, Inc.: Wallingford, CT, 2009.

(47) Peterson, K. A.; Shepler, B. C.; Figger, D.; Stoll, H. On the Spectroscopic and Thermochemical Properties of $\mathrm{ClO}, \mathrm{BrO}, \mathrm{IO}$, and Their Anions, J. Phys. Chem. A 2006, 110, 13877-13883.

(48) Feller, D. The Role of Databases in Support of Computational Chemistry Calculations, $J$. Comp. Chem. 1996, 17, 1571-1586.

(49) Schuchardt, K. L.; Didier, B. T.; Elsethagen, T.; Sun, L.; Gurumoorthi, V.; Chase, J.; Li, J.; Windus, T. L. Basis Set Exchange: A Community Database for Computational Sciences. J. Chem. Inf. Model. 2007, 47, 1045-1052.

(50) Riplinger, C.; Neese, F. An Efficient and Near Linear Scaling Pair Natural Orbital Based Local Coupled Cluster Method. J. Chem. Phys. 2013, 138, 034106.

(51) Riplinger, C.; Sandhoefer, B.; Hansen, A.; Neese, F. Natural Triple Excitations in Local Coupled Cluster Calculations with Pair Natural Orbitals. J. Chem. Phys. 2013, 139, 134101.

(52) Weigend, F.; Ahlrichs, R. Balanced Basis Sets of Split Valence, Triple Zeta Valence and Quadruple Zeta Valence Quality for H to Rn: Design and Assessment of Accuracy. Phys. Chem. Chem. Phys. 2005, 7, 3297-3305.

(53) Neese, F. The ORCA Program System. Wiley Interdiscip. Rev. Comput. Mol. Sci. 2012, 2, 73-78. 
(54) Hellweg, A.; Hättig, C.; Höfener, S.; Klopper, W. Optimized Accurate Auxiliary Basis Sets for RI-MP2 and RI-CC2 Calculations for the Atoms Rb to Rn. Theor. Chem. Acc. 2007, 117, 587-597.

(55) Hill, J. G.; Peterson, K. A. Correlation Consistent Basis Sets for Explicitly Correlated Wavefunctions: Pseudopotential-Based Basis Sets for the Post-d Main Group Elements Ga-Rn. J. Chem. Phys. 2014, 141, 094106.

(56) Werner, H.-J.; Knowles, P. J.; Knizia, G.; Manby, F. R.; Schütz, M.; Celani, P.; Györffy, W.; Kats, D.; Korona, T.; Lindh, R.; et al. MOLPRO, version 2015.1, a package of ab initio programs, 2015; see http://www.molpro.net.

(57) Peterson, K. S.; Adler, T. B.; Werner, H.-J. Systematically Convergent Basis Sets for Explicitly Correlated Wavefunctions: The Atoms H, He, B-Ne, and Al-Ar. J. Phys. Chem. 2008, $128,084102$.

(58) Blades, A. T.; Klassen, J. S.; Kebarle, P. Free Energies of Hydration in the Gas Phase of the Anions of Some Oxo Acids of C, N, S, P, Cl, and I. J. Am. Chem. Soc. 1995, 117, 1056310571.

(59) Hiraoka, K.; Mizuse, S.; Yamabe, S. Solvation of Halide Ions with $\mathrm{H}_{2} \mathrm{O}$ and $\mathrm{CH}_{3} \mathrm{CN}$ in the Gas Phase. J. Phys. Chem. 1988, 92, 3943-3952.

(60) Mohr, C.; Lopez-Hilfiker, F. D.; Zotter, P.; Prévôt, A. S. H.; Xu, L.; Ng, N. L.; Herndon, S. C.; William, L. R.; Franklin, J. P.; Zahniser, M. S.; et al. Contribution of Nitrated Phenols to 
Wood Burning Brown Carbon Light Absorption in Detling, United Kingdom During Winter Time. Environ. Sci. Tech. 2013, 47, 6316-6324.

\section{TOC Graphic}

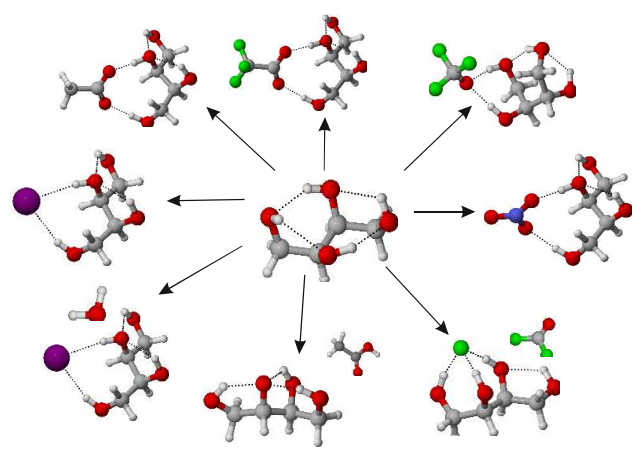

ACS Paragon Plus Environment 